\title{
La cerámica altomedieval de Tortosa (siglos VII-X). Una primera clasificación y análisis interpretativo
}

\author{
Early medieval pottery of Tortosa (7th-10th centuries). A first classification \\ and interpretative analysis
}

Joan Negre Pérez *

\begin{abstract}
RESUMEN
El objetivo de este trabajo es presentar una primera sistematización del registro cerámico de producción regional del territorio de Tortosa entre la Antigüedad Tardía y la Alta Edad Media (siglos VII-X). Los materiales estudiados proceden de una campaña bianual de prospecciones llevada a cabo en las comarcas del Montsià y el Baix Ebre, y de la revisión de los fondos del Museu de les Terres de l'Ebre. Las producciones cerámicas son -por su abundanciauno de los elementos clave en el estudio histórico, pudiendo aportar información sobre la cronología de los yacimientos, su organización interna y las dinámicas territoriales en las que se insertan. Pese a las limitaciones que imponen los métodos superficiales de recogida y el análisis de materiales de museo, en muchos casos descontextualizados, hemos tratado de establecer unas primeras pautas básicas en relación a estas producciones. En ausencia de trabajos de este tipo, resultaba imperativa una catalogación de este registro que permitiera identificar estos materiales en las decenas de excavaciones que se llevan a cabo anualmente en el territorio tortosino. Más allá de su aplicación práctica, se reflexiona en el texto sobre la información histórica que es capaz de aportar la cerámica en relación al proceso de islamización de al-Andalus.
\end{abstract}

Palabras clave: Tortosa, cerámica altomedieval, tipología, Islamización, Emirato Andalusí

Este trabajo plasma algunos de los resultados de un proyecto específico de investigación arqueológica incluido dentro del desarrollo de nuestra tesis doctoral ${ }^{1}$. Hemos estructurado el texto en diversos bloques temáticos: en primer lugar, unas breves indicaciones sobre el marco geográfico donde se ha llevado a

\begin{abstract}
The objective of this work is to present a first classification of the early medieval pottery production in Tortosa, between 7 th and 10th centuries. This record come from two years of archaeological fieldwork carried out in the southern Catalan territories, as well as the review of the museum collections. Pottery productions are one of the key factors in historical research, due to its own abundance in archaeological sites. They can provide valuable information about the chronology and social organisation of archaeological sites as well as a better understanding of territorial dynamics. Despite the limitations of survey methods in order to study pottery productions, most of them not linked to an archaeological context, we tried to establish a preliminary study scheme. Lacking previous works, it was necessary this first classification for the purpose of provide a useful guide to help in the large amount of archaeological excavations carried out in Tortosa's region. Beyond its practical application, the influence of this record in the knowledge of al-Andalus Islamisation process is analysed throughout the text.
\end{abstract}

Keywords: Tortosa, early medieval pottery, typology, Islamisation, Andalusian Emirate

cabo esta investigación; a continuación, un sucinto estado de la cuestión en torno a la problemática tratada; en tercer lugar, el cuerpo propiamente dicho de este trabajo, en forma de un primer ensayo tipológico de las producciones regionales cerámicas de Tortosa entre la Antigüedad Tardía y el Mundo Islámico

\footnotetext{
* Universitat Autònoma de Barcelona - Departament de Ciències de l'Antiguitat i de l'Edat Mitjana
} 
(siglos VII-X); y por último, una breve reflexión del papel de la cerámica como indicador del proceso de islamización, realizada a partir del análisis de los datos obtenidos y de las informaciones históricas construidas a partir de estos. Así pues, en las próximas páginas queremos realizar una primera propuesta de clasificación del registro cerámico altomedieval, una cuestión de vital importancia que ha sido totalmente desatendida durante décadas. Su desconocimiento en este ámbito territorial y cronológico era absoluto hasta la realización de este proyecto de investigación, lo que nos permite ofrecer ahora una primera guía de referencia para la identificación de este tipo de materiales en las intervenciones realizadas en la región.

\section{CONCRECCIÓN DEL TERRITORIO DE ESTUDIO}

El área en la que se ha desarrollado este trabajo, que toma como base una campaña bianual de prospección arqueológica, está limi- tada por motivos administrativos a las actuales comarcas catalanas del Baix Ebre y el Montsià, que muestran una correspondencia perfecta con los límites que se establecen para el territorio de la ciudad de Tortosa en su carta de población de 1149. El curso inferior del río Ebro configura el eje central de este territorio, al delimitar una unidad geomorfológica bien definida. No obstante, otros dos ámbitos se incluyen también en este marco geográfico: el sistema montañoso litoral catalán, al Este, y las últimas estribaciones del sistema ibérico al Oeste.

\section{EL ESTUDIO DE LA TRANSICIÓN DE LA ANTIGÜEDAD AL MUNDO ISLÁMICO A TRAVÉS DEL REGISTRO CERÁMICO}

Posiblemente, el estudio histórico del proceso de formación de la sociedad andalusí ha tenido en el análisis de las producciones cerámicas uno de sus indicadores más fiables. Éste nos proporciona información de gran utilidad para la comprensión de los procesos internos de cada yacimiento así como para la

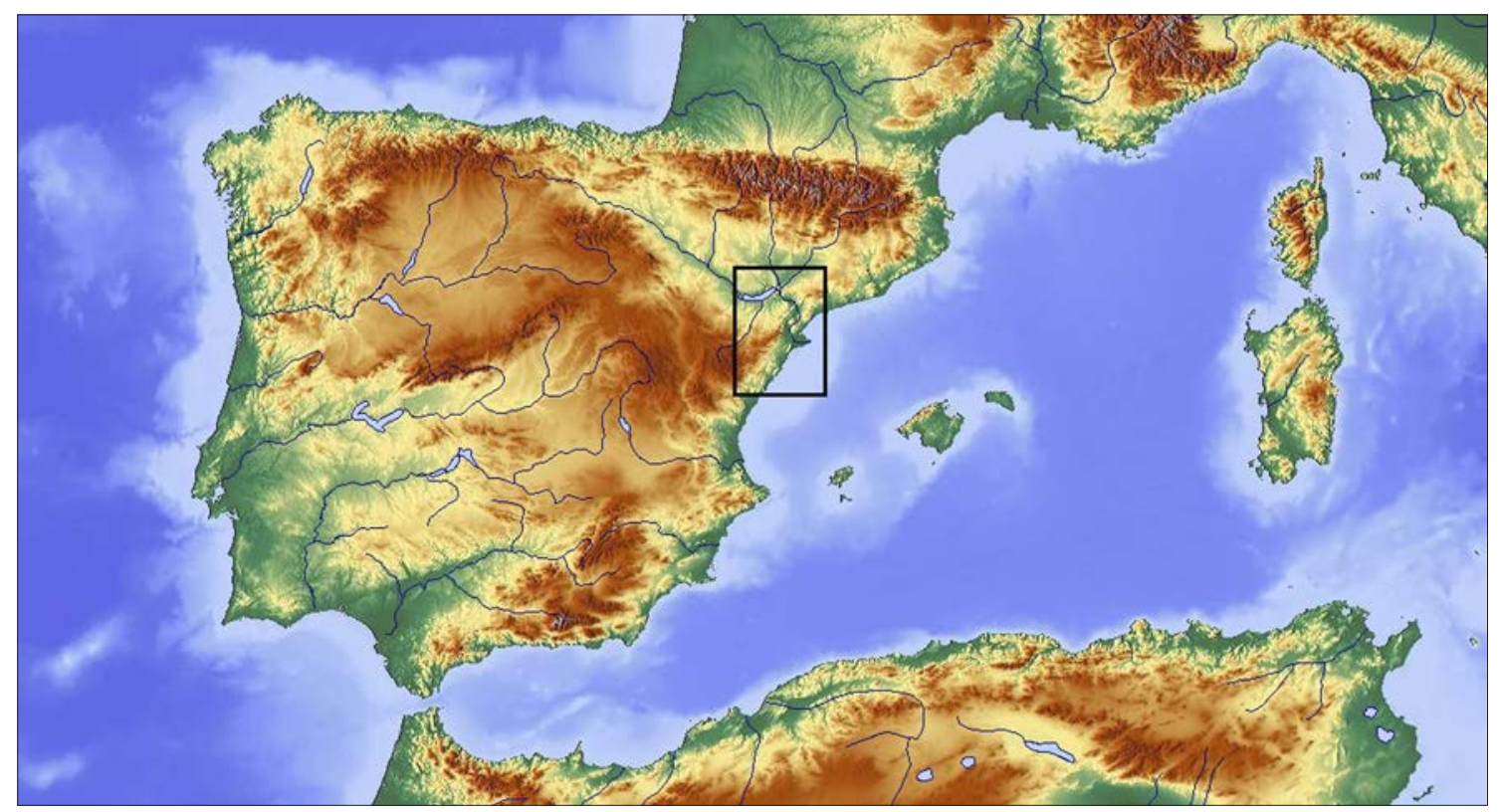

Fig. 1. Situación del territorio de Tortosa en el contexto Mediterráneo

1 Este proyecto específico, subvencionado por la Direcció General del Patrimoni Cultural de la Generalitat de Catalunya (IA2010-56400) se encuentra vinculado al proyecto marco "Organización fiscal y ocupación del territorio durante la Alta Edad Media" (HAR200907874), dirigido por el Dr. Ramon Martí Castelló e incluido dentro del Grupo de Investigación OCORDE (2009SGR-727). Su resultado final ha sido la tesis doctoral del autor, defendida en Abril de 2013 bajo el título de: "De Dertosa a Ṭurțǔša. L'extrem oriental d’al-Tagr al-A'là en el context del procés d'islamització d’al-Andalus" (Consulta en línea: http://www.tdx.cat/handle/10803/116319). 
datación de estos en su contexto diacrónico. No se trata de entender la cerámica como un fósil director con el que establecer unos hitos cronológicos para cada yacimiento sino más bien de las posibilidades que, como conjunto, ofrece para entender las transformaciones en las pautas de ocupación del territorio y en sus modelos productivos. Su estudio supone, por tanto, un primer paso ineludible con el objetivo de abarcar diversas cuestiones de calado para la investigación histórica, la más importante de las cuales sería la relación entre producción y productores, es decir, entre economía y sociedad.

De la reflexión en torno a la evolución de estas producciones surgieron durante los años 90 los primeros planteamientos que situaron este período histórico de amplias transformaciones en el punto de mira de una incipiente Arqueología Medieval. Este fue el principal laboratorio de experimentación para estudiar los cambios más relevantes entre las estructuras productivas tardo-antiguas e islámicas, centrando su punto de mira en la detección de los principales grupos sociales que intervinieron en los mismos (ACIÉN, 1986 y 1993; GUTIÉRREZ, 1988 y 1996; ACIÉN y MARTÍNEZ, 1989; RETUERCE, 1990; BAZZANA, 1990; PASCUAL et alii, 1997). Esta identificación se podía establecer mientras los modelos productivos regionales fuesen discernibles, siendo prácticamente imposible el análisis con posterioridad a la instauración del Califato, que conllevó una relativa homogeneización de la vajilla andalusí. La culminación de esta transformación se vio acompañada por la creación de extensas y bien organizadas redes de distribución, así como de mercados y circuitos comerciales que propiciaron la estandarización de estas producciones. El estudio de las variaciones en las formas de producir, distribuir y consumir la cerámica es, por tanto, un indicador tanto cronológico como social, de los ritmos de imposición de la nueva Formación Social Andalusí frente al resto de formaciones sociales participantes en este proceso (GUTIÉRREZ, 2007: 307).

Esta transformación, que tiende progresivamente hacia la homogeneidad de las pro- ducciones y que contribuirá en gran medida a la difusión propagandística de la autoridad pública andalusí, evolucionará con ritmos diversos dependiendo del territorio, así como si se trata del ámbito urbano o rural (ALBA y GUTIÉRREZ, 2008: 588). Las precisiones que se puedan realizar para los contextos propios de la ciudad, bien excavados principalmente a partir de intervenciones de urgencia, serán mucho mayores que en el medio agrícola, donde excavación y prospección dependen en mayor manera de actuaciones programadas por las principales instituciones de investigación. Gracias, no obstante, a algunos estudios de casos urbanos emblemáticos, como por ejemplo el del yacimiento arqueológico del Tolmo de Minateda (Hellín, Albacete), o las ciudades de Valencia o Tortosa, en su día se pudieron precisar las tendencias particulares de unos territorios que, en líneas generales, sirvieron para describir este proceso en el área levantina. Finalmente, y con la suma progresiva de cada vez más estudios regionales, se consiguió identificar las principales fases de transformación de las formas de producción cerámica en este ámbito.

Estos trabajos regionales identificaban entre los siglos $V$ y VI, genéricamente, un decrecimiento progresivo de las importaciones norte-africanas y orientales, llegando a desaparecer prácticamente durante el último cuarto de esta centuria, algunas décadas más tarde en el caso de las ánforas orientales en ciertos ámbitos como el tarraconense (MACIAS y REMOLÁ, 2005: 127). En otros casos cercanos, como el de la ciudad de Valencia, la pervivencia durante buena parte del siglo VII de estos materiales parece fuera de toda duda (PASCUAL et alii 2003: 107). Es durante esta última centuria sin embargo cuando empieza a apreciarse con claridad una intensa actividad local y regional de producción de cerámicas para su uso en un ámbito más restringido. El universo productivo de esta centuria era, a pesar de su regionalización, mucho más complejo de lo que se había considerado tradicionalmente, principalmente en las ciudades, las cuales se demostró que aún mantenían una remarcable actividad urbana. Los ciclos productivos y la actividad comercial mantendrían unas producciones 
cerámicas que no podían ser caracterizadas como simples o toscas, pues mantuvieron la calidad de sus pastas y presentaban unos modelados habitualmente a torno (GUTIÉRREZ et alii, 2003: 161).

El siglo VIII presentaba una mayor dificultad de identificación, con contextos de estudio basados en ámbitos pre-islámicos con continuidad de ocupación, como en los ejemplos de los conjuntos episcopales de Eio (GUTIÉRREZ, 2007: 302) o Valentia (BLASCO et alii, 1994: 370-372; PASCUAL et alii, 2003: 108; RIBERA, 2008: 317-318). Los principales materiales detectados en algunos de estos contextos correspondían a producciones comunes, mayoritariamente de cocina, donde destacaban marmitas, ollas o cazuelas. No obstante, la homogeneidad de las cerámicas regionales permitió identificar con claridad el horizonte altomedieval correspondiente al siglo IX, que según esta misma propuesta se mantendría hasta la segunda mitad del siglo X, cuando la implantación del califato forzó a la estandarización de los modelos productivos.

El estudio de la producción cerámica no proporciona únicamente unas pautas básicas para el encuadramiento cronológico de este registro y de los yacimientos que lo contienen, sino que aporta informaciones de gran importancia sobre las dinámicas históricas que se desarrollaron durante el período en que fue realizada. El proceso de islamización, es decir, el conjunto de transformaciones acontecidas en el territorio peninsular que condujeron a la consolidación de la nueva sociedad andalusí, es uno de los aspectos más relevantes que nos permite estudiar la cerámica. Es de la interrelación entre los datos procedentes del estudio cerámico y otras fuentes de información, tanto escritas como arqueológicas, de donde pudieron inferirse finalmente nuevos modelos explicativos de este proceso histórico. La conclusión a la que se llegó en su momento a partir de este primer encuadre ceramológico, fue la de presentar la Islamización como una dinámica de larga duración y un ritmo lento de consolidación. Se trata, pues, de un ámbito de estudio complejo en el que únicamente a partir de la contrastación entre diversas aproximaciones territoriales de carácter diacrónico se pueden establecer unas tendencias generales. Observemos, por tanto, si nuestro trabajo confirma o refuta la hipótesis planteada por la historiografía en el caso concreto de nuestro territorio de estudio.

\section{PROPUESTA DE CLASIFICACIÓN TÉCNICA DE LAS PRODUCCIONES CERÁMICAS}

En este apartado queremos proponer una primera tipología técnica de las producciones de ámbito regional manufacturadas en el territorio de Tortosa entre la Antigüedad Tardía y la Alta Edad Media. Esta taxonomía se ha realizado a partir del análisis de los más de 5.000 fragmentos recogidos en el campo o aportados por los fondos de museo, indexados en una base de datos en la que se ha catalogado el conjunto de piezas bajo estudio a partir del criterio de número mínimo de individuos (NmI). Así, finalmente se han recopilado las características principales de 601 elementos, los cuales han sido usados para la creación de una clasificación de estas producciones. Aunque la mayoría del registro responde a conjuntos descontextualizados estratigráficamente, el análisis estadístico de esta base de datos esperamos que aporte algunas pautas generales sobre la producción cerámica en este ámbito geográfico. La cronología de los grupos técnicos obtenidos, por tanto, proviene de la relación cruzada entre los datos obtenidos, algunos de los cuales sí se encuentran bien documentados y la información procedente de excavaciones cercanas.

\section{Principales características técnicas}

En primer lugar, trataremos de sistematizar el conjunto de características macroscópicas recogidas durante el análisis de los materiales cerámicos. A partir de estos datos se podrán posteriormente inferir una serie de conclusiones provisionales respecto a las características técnicas de estas producciones y como estas pueden ayudarnos a identificar una serie de grupos de control. 


\section{LA COMPOSICIÓN DE LAS PASTAS}

La composición básica de las pastas cerámicas se basa en una mezcla de arcillas y feldespatos fundentes con una mayor o menos cantidad de inclusiones, dependiendo de su calidad. Los estudios realizados en algunos talleres medievales indican que las extracciones de estos componentes se llevarían a cabo en yacimientos muy cercanos a los talleres. Las características geológicas del territorio tortosino propician un fácil acceso a los mismos directamente a cielo abierto, puesto que al igual que en la mayor parte del litoral mediterráneo peninsular, los niveles arcillosos aparecen en cotas muy superficiales. La similitud entre las composiciones químicas del registro cerámico procedente del levante peninsular ha sido explicada a partir del uso de un mismo nivel geológico de arcillas como base para su elaboración (BAZZANA et alii, 1986: 35-37). Es, por tanto, únicamente a partir del estudio de las inclusiones presentes en estas pastas que pueden advertirse algunas tendencias locales específicas.

Los desgrasantes, sin embargo, parecen estar muy vinculados a ciertos grupos morfofuncionales, los destinados a ser usados en el fuego, y su tamaño y presencia disminuyen progresivamente según avanzan las técnicas de procesado y decantación de las arcillas, eliminando las inclusiones naturales y dejando únicamente las intencionadas. Cuatro serían los grupos más abundantes en nuestra zona de estudio: las cuarcitas, las micas, los feldespatos y las calcitas, así como en menor proporción la chamota. De entre estos, el único grupo de minerales que resulta estadísticamente relevante para la diferenciación productiva de estos fragmentos han sido las micáceas, que aparecen abundantemente en las producciones regionales tempranas y que progresivamente tenderían a desaparecer en las piezas más modernas y con pastas más depuradas. El estudio detallado de los contextos en los que estas aparecen con mayor abundancia indicaría que se trata en su mayoría de producciones anteriores a la estandarización productiva califal, y sobretodo vinculadas a ciertos tipos morfológicos cuya manufactura debía estar vinculada a los talleres locales, como ollas, jarras, cántaros o jarritos. Se trata de una característica que ha sido destacada también en otros puntos del levante peninsular para las producciones regionales anteriores al siglo X (BAZZANA, 1986: 94-96; BLASCO et alii, 1994: 370-372; PASCUAL et alii, 2003: 108-110).

\section{EL MODELADO}

Tradicionalmente, las producciones cerámicas de este período han tendido a dividirse en tres grupos de modelado: cerámicas realizadas a mano, a torneta o a torno. En muchos casos, no obstante, estas tres opciones son complementarias entre sí, pudiendo diferenciarse las partes de una pieza realizadas con una u otra técnica. La mayoría de las piezas que hemos analizado durante este estudio parecen mostrar una serie de características que, si bien no confirman el uso de torneta, sí al menos alguna tipología de torno más sencilla que los de época califal o taifa. Entre estos indicadores podemos destacar, por ejemplo, las irregularidades extremas en el grosor de las paredes de las piezas o la ausencia de las características marcas de rodamiento acelerado en la superficie de las vasijas.

En las piezas más completas que se conservan en el Museu de les Terres de l'Ebre (Amposta), pueden incluso advertirse en las bases de algunas ollas y cazuelas marcas de materiales orgánicos, un indicador que en otros contextos ha servido para la identificación del modelado con torneta (GUTIÉRREZ, 1996: 54 y sig.). Sin embargo, la elección de una u otra técnica no estaría tan relacionada con la capacidad técnica de los artesanos sino con la adecuación de los modelos productivos y sus necesidades funcionales. A partir del siglo $X$ parece que se documentarían ya en la ciudad de Tortosa algunos talleres especializados que dispondrían de tornos tanto para las producciones más elaboradas como para enseres de uso cotidiano (CURTO et alii, 1984: 63-65), por lo que la mayor parte de la cerámica que responde a estas características indicadas debería relacionarse con unas formas de producción más simples anteriores al califato. 


\section{LOS TRATAMIENTOS SUPERFICIALES}

Aunque no suponen un conjunto muy extenso dentro del total de muestras analizadas, los tratamientos superficiales más usados en el registro cerámico tortosino son el alisado, el raspado y el bruñido. Espacialmente, el bruñido es utilizado únicamente en las producciones cercanas al Castillo de Amposta, principalmente las procedentes del yacimiento del Pla d’Empúries (Amposta), donde creemos que podría haber existido un centro alfarero local vinculado a esta fortificación. En cuanto al alisado de la superficie de algunas piezas, se identifica un tratamiento que ofrece a estas vasijas un acabado más depurado y brillante, adquirido a partir de la fricción de las paredes de estas con un paño húmedo o una pequeña espátula de madera una vez realizado el modelado. La diferenciación de este tipo de acabados respecto a los revestimientos arcillosos es únicamente perceptible a partir del análisis con láminas finas (CAPELLI y CABELLA, 2004: 126), aunque el grosory el acabado poco homogéneo de estas técnicas superficiales podrían permitir aventurar su identificación macroscópica.

\section{LAS DECORACIONES}

Una de las principales características que nos permiten identificar diferentes grupos tipológicos cerámicos han sido las decoraciones aplicadas sobre estos enseres, identificativas de talleres de producción con un ámbito de distribución limitado. Con la formalización de estas observaciones se ha podido realizar una primera propuesta de clasificación técnica de las mismas, en la que destacan dos tipos decorativos principales: las decoraciones incisas y las impresas. De entre las decoraciones incisas, las más destacadas son: las estriadas, con una o varias líneas paralelas al plano de la pieza y con momentos de realización sucesivos; las peinadas, con varios trazos completamente paralelos al plano de la pieza y realizados simultáneamente; y finalmente los acanalados, realizados con una pequeña lámina de madera con el borde dentado, que le darían un característico acabado escalonado, en evolución durante todo el período islámico hacia motivos cada vez más definidos. La localización de estas decoraciones es principalmente el cuello de diversos tipos morfológicos, principalmente ollas y jarras. Una de las problemáticas que plantea la identificación de estos motivos decorativos deriva del desgaste post-deposicional sufrido por las piezas, que en muchos casos muestran unas superficies altamente erosionadas.

Otra de las técnicas específicas de esta área son sin lugar a dudas las asas con decoraciones estriadas helicoidales, llamadas comúnmente asas retorcidas por su apariencia similar a la de una soga retorcida (Fig. 10). Se trata de asas tubulares a las cuales se les habría aplicado una decoración incisa en forma de espiral a lo largo de su superficie, dándoles así una cierta apariencia de torsión y mejorando el agarre de las mismas. Aparecen mayoritariamente en ciertos tipos de cántaros que como veremos posteriormente parecen provenir de una tradición productiva de época tardo-antigua y origen norte-africano, y que seguirían produciéndose durante el período andalusí. Son también los cántaros, en este caso de un tipo formal distinto, dónde encontramos un nuevo elemento decorativo característico de estas producciones regionales como son las asas de sección elíptica en las que se combinan diseños incisos e impresos.

En cuanto a las decoraciones pintadas cabe destacar que, a pesar de estar bien documentadas durante el emirato en otros ámbitos peninsulares (CASTILLO, 1996: 200; GUTIÉRREZ, 1999: 85; CASAL et alii, 2005: 193), este tipo de motivos no han podido ser detectados en nuestros contextos más antiguos. Es posible que dada la importancia que un puerto como el de la ciudad de Tortosa jugó durante los primeros siglos de dominación andalusí, con una activa comunidad marinera instalada en este territorio (BALLESTÍN, 1999: 63-66), nuevas excavaciones pudiesen arrojar más luz sobre esta cuestión. En el actual estado de la investigación, debemos atenernos a los resultados obtenidos durante las primeras intervenciones arqueológicas de carácter urbano en la ciudad de Tortosa, donde se fijó la cronología de estas producciones pintadas, principalmente 
con líneas de óxido de manganeso paralelas al plano de la pieza, dentro de contextos de la segunda mitad del siglo XI y la siguiente centuria (CURTO, LORIENTE y MARTÍNEZ, 1984: 42). Posteriores excavaciones urbanas (CURTO y MONTAÑÉS, 2009: 28 y 42-43), incluidas las recientes intervenciones arqueológicas en el Castell de la Suda (GRIÑO et alii, 2013: 354-356), o la revisión de los materiales del cercano Museu de Balaguer (ALÒS y SOLANES, 2010: 90-97), han referenciado estas mismas producciones en contextos arqueológicos igualmente tardíos.

\section{LOS REVESTIMIENTOS}

Aunque las cubiertas vítreas componen uno de los aspectos técnicos más habituales entre las producciones cerámicas andalusíes, la aplicación de esta solución en los contextos que hemos podido identificar como anteriores al califato ha sido ínfima y no permite generalizarlas. El vidriado de las piezas cerámicas nos sitúa ante una cuestión actualmente bajo discusión, como es la diferenciación entre una posible tradición de revestimiento vítreo tardo-antigua y otra de procedencia oriental. Respecto a la primera, cabe destacar los casos del Tolmo de Minateda (Albacete) (GUTIÉRREZ et alii, 2003: 134), Valencia (PASCUAL et alii, 2003: 99), Tarragona (MACíAS, 1999: 277) e incluso Barcelona (BELTRÁN, 2005: 75), todos ellos datados entre los siglos VII y VIII, y con un característico tono marrón parduzco. Se trata, sin embargo, de unas producciones que no parecen estar presentes en los contextos tardíos de la ciudad de Tortosa. Aún así, al tener en cuenta las formas en las que aparece este tipo de cubierta, habitualmente ollas de borde vuelto, y el espesor de esta capa en la mayoría de los materiales estudiados, algunos autores plantean la posibilidad de que pueda tratarse de restos de un proceso de manufactura de vidrio y no de la aplicación específica de un revestimiento vítreo (GUTIÉRREZ et alii, 2003: 134).

En cuanto a la segunda tradición, la de origen oriental, parece que los primeros ejemplos que se han podido sistematizar de cerámica vidriada de cronología andalusí temprana se circunscriben al tercio sur de la Península (CASTILLO et alii, 1986; GUTIÉRREZ, 1999: 83; SALINAS, 2012:
230-232). Estas producciones, probablemente importadas y distribuidas hacia el resto de la península desde Pechina (Almería), suponen una primera muestra, previa a su manufactura local (ACIÉN y MARTínEZ, 1989: 134). LOS primeros centros productores de vidriado de tradición islámica en al-Andalus se ubicaron por tanto en el sudeste peninsular, siendo quizás los de Pechina, Málaga y Murcia los más tempranos (ACIÉN, 1993: 171). Se trata en todo caso de revestimientos imperfectos y poco depurados, con esquemas de color monocromos en verde o melado o bícromos con una combinación de los anteriores, y que muestran en algunos casos sencillos motivos decorativos en manganeso bajo el vedrío. En cualquier caso, cabe destacar que este tipo de soluciones técnicas no parece llegar al área de Tortosa hasta fechas posteriores, probablemente durante el califato, vinculadas principalmente a formas de servicio de mesa, como ataifores o jarras.

Otro tipo de revestimiento analizado son las cubiertas arcillosas, bien de tipo engobe $\mathrm{o}$, en la mayoría de casos, debidas a tratamientos de impermeabilización a través del alisado o el esclarecimiento superficial de las piezas (CAPELLI y CABELLA, 2004: 126). Esta técnica puede ser casual pero en muchos casos es evidente su intencionalidad, lo que denota un importante conocimiento técnico a partir del uso de sal o agua de mar en la preparación de las arcillas y del control de las condiciones de cocción y oxigenación durante el proceso de cocción (CAPELLI y MANNONI, 1996). Este es el tipo de revestimiento mayoritario en los contextos tortosinos de entre las piezas que hemos identificado en el grupo técnico correspondiente. En otros casos, el uso de engobes sobre las piezas una vez secas y con anterioridad a la cocción puede determinarse a partir del uso de un microscopio sobre secciones transversales y permite un acabado más bien definido. Así sucede con el caso de piezas con engobe rojo, poco presentes en el registro emiral y más abundantes en contextos de la ciudad de Tortosa a partir del califato, de las que se han podido detectar unos pocos paralelos en la Península, principalmente en Lleida (LORIENTE, 2000: 296), Murcia (NAVARRO, 1990: 36), Córdoba (CANO, 2007: 151) y el altiplano central (RETUERCE, 1990: 151). 


\section{EL PROCESO DE COCCIÓN}

Cuatro son los grupos principales de procesos de cocción que podrían distinguirse en las piezas estudiadas, diferenciando en estos de una primera fase de horneado y una segunda de enfriamiento de la pieza. Así, se identificarían procesos de cocción y enfriamiento en atmosfera reductora u oxidante, así como procesos mixtos de cocción en atmosfera reductora u oxidante y enfriamiento inverso. Estas dinámicas, observables en la coloración de las pastas, serían identificativas de los tipos de hornos y de los procesos productivos llevados a cabo para la elaboración de los elementos cerámicos. La elaboración de producciones cerámicas en atmosferas únicamente oxidantes es técnicamente más compleja de conseguir, y por ello minoritaria respecto a los procesos mixtos en los contextos emirales. Así pues, los medios de producción más simples que pueden definir las producciones locales propias de la Alta Edad Media en el área de Tortosa, parecen haber optado en su mayoría por unos procesos de cocción reductora y enfriamiento oxidante o irregular.

Este tipo de elaboración respondería en su mayoría a hornos al aire libre o de cámara única, que principalmente funcionarían a partir de la difusión del calor por contacto directo o por convección. Con la aparición de nuevos talleres urbanos en una fecha más avanzada se generalizarían otros tipos de hornos, con doble cámara, con producciones vinculadas a una cocción y enfriamiento en atmósfera oxidante. A pesar de estas apreciaciones generales, cabe destacar que el proceso de cocción de las piezas cerámicas es una técnica que dependería en gran medida de aspectos regulables por el artesano. Así, la apertura de la cámara de cocción durante su procesado, la exclusión de oxígeno o los distintos tipos de combustible usados, podrían aportar unos acabados característicos y con diferentes grados de coloración de las piezas. Por tanto, las observaciones realizadas sobre los materiales estudiados únicamente nos aportan unas tendencias generales en el uso de ciertos modelos productivos pero que en ningún caso pueden ser tomadas como absolutas.

\section{Grupos técnicos y propuesta cronológica}

El análisis de la base de datos conformada por el conjunto de observaciones realizadas sobre nuestra muestra de estudio nos ha permitido establecer una serie de grupos preliminares en los que encuadrar las producciones cerámicas a partir de sus características técnicas descritas anteriormente. El método estadístico usado ha sido la clasificación de clusters o conglomerados por procedimientos jerárquicos, basados en la similitud y agrupación en conjuntos de variables multi-estado (ESQUIVEL, 1988). Este tipo de análisis se basan en la representación de un reducido conjunto de grupos definidos por su afinidad respecto a una serie de características o atributos. En nuestro caso, el espacio de variables viene definido por tres factores: la incertidumbre en la ocurrencia de uno de los estados de la variable, el nombre de estados de esta variable y finalmente su frecuencia de aparición (ESQUIVEL et alii, 1991: 54). Los grupos resultantes serán definidos por una alta homogeneidad interna y una alta heterogeneidad externa, y aunque las técnicas de clasificación pueden recibir distintos nombres, el objetivo clasificador es común a todas ellas.

De la interpretación de estos clusters resultantes y su agrupación en grupos técnicos coherentes dependerá en gran parte el éxito de esta metodología. A partir de la correlación entre los conglomerados obtenidos y los contextos arqueológicos donde se han localizado, así como con la ayuda de casos paralelos en los que estos han sido también descritos, hemos realizado una propuesta cronológica de las formas de producción cerámica en nuestro territorio. En cualquier caso se trata de una hipótesis de trabajo a partir de los datos de que actualmente se disponen que esperamos sirva de guía para futuros estudios en esta zona. Únicamente a partir de la excavación de futuros casos siguiendo una metodología estandarizada y con dataciones absolutas para los diferentes niveles seremos capaces de matizar o confirmar esta primera aproximación. Observemos, por tanto, los resultados obtenidos en esta primera propuesta de ensayo tipológico para el período comprendido entre los siglos VII y X. 


\section{GRUPO TÉCNICO 1 (GT1). CERÁMICA COMÚN DE COCCIÓN REDUCTORA}

Este grupo estaría caracterizado por unos materiales modelados a torneta o con un torno de rotación irregular, principalmente ollas, con abundantes proporciones de inclusiones añadidas, en su mayoría micáceas, que les aporta una característica textura microporosa con pequeños elementos brillantes. También contaría entre sus inclusiones con pequeños fragmentos de cuarcitas, que en algunos casos habrían dejado su impronta a través de múltiples vacuolas de pequeño tamaño. Durante su horneado y enfriamiento, se mantiene una atmosfera de cocción con ausencia de oxígeno, lo que les atribuye una característica coloración negruzca, tanto en su interior como en su superficie. Parecen presentar en algunos casos tratamientos superficiales de alisado, raspado o presión manual de sus paredes con el objetivo de compactar sus pastas, dejando en algunos casos los cuellos ligeramente más voluminosos y sus labios redondeados o biselados. Las decoraciones más habituales, presentes en la práctica totalidad de estos materiales son peinadas o estriadas. Se trataría de un conjunto productivo bastante homogéneo del que encontramos paralelos a los que se les atribuye una cronología entre los siglos VII y IX en el yacimiento de la Plaça de l'Olivera (CURTO et alii, 1984: 11) y en diversos contextos del siglo VII (PASCUAL et alii, 2003: 100 y 108-110) y posteriores (BLASCO et alii, 1994: 370-372) en la ciudad de Valencia.

\section{GRUPO TÉCNICO 2 (GT2). CERÁMICA COMÚN DE COCCIÓN IRREGULAR}

Este grupo técnico es característico de un conjunto formado principalmente por ollas y jarritos, de pastas con abundantes inclusiones micáceas y con presencia de calcitas en su base arcillosa, lo que les aportaría una coloración externa ligeramente amarillenta. De nuevo presentan una superficie porosa y rugosa, con unos procesos de cocción fuertemente irregulares, pero en los que se puede apreciar la existencia de aportación de oxígeno durante su enfriamiento. Sus decoraciones más habituales son las incisiones estriadas y peinadas, así como unos labios habitualmente biselados, unas tendencias que se observarían nuevamente durante la fase tardo-antigua y alto-medieval de las ciudades de Tortosa (CURTO et alii, 1984: 11) y Valencia (BLASCO et alii, 1994: 370-372). Se plantea por tanto para este grupo técnico una cronología entre los siglos VII y IX, que poco a poco iría desapareciendo para dejar paso a los materiales correspondientes al GT4.

\section{GRUPO TÉCNICO 3 (GT3). CERÁMICA GRO- SERA DE COCCIÓN IRREGULAR}

De nuevo observamos un grupo técnico extremadamente similar al GT2, pero con la diferencia de contar con unas inclusiones de tamaños mucho mayores y con un proceso de depurado de las arcillas de menor calidad. También contaría entre sus inclusiones con pequeños fragmentos de cuarcitas, que en algunos casos habrían dejado su impronta a través de múltiples vacuolas de un tamaño considerable. Se trataría de un conglomerado basado en piezas para la cocción de alimentos, principalmente cazuelas, por lo que las aportaciones externas de minerales suelen ser habituales para combatir los cambios extremos de temperatura y evitar su quebradura. Además de esta diferencia, las piezas correspondientes a este grupo carecen de decoración alguna y en la mayoría de casos disponen de asas o mamelones, en algunos casos con pequeñas marcas de punzón. Los contextos en los que aparecen materiales con estas características técnicas, así como los grupos morfológicos en los que es más habitual, indicarían una cronología de finales de la Antigüedad Tardía (ss. VII-VIII).

\section{GRUPO TÉCNICO 4 (GT4). CERÁMICA COMÚN DE COCCIÓN ÓXIDO-REDUCTORA}

Se trata de un grupo caracterizado por unas pastas con abundantes inclusiones micáceas y un modelado aún fuertemente irregular. Su característica principal, sin embargo, se encuentra en la aportación controlada de oxígeno de forma generalizada durante su proceso de enfriamiento. Los grupos morfo- 
lógicos más habituales en los que aparece son las ollas, los cántaros y las cazuelas. Las asas presentes en algunas formas de almacenamiento de líquidos como los cántaros muestran además decoraciones estriadas y punteadas combinadas, en el caso de las asas planas, y con estrías helicoidales en el caso de las tubulares, también llamadas asas retorcidas. Encontramos materiales precedentes con similitudes morfológicas del primer tipo en los niveles tardo-antiguos del yacimiento de la Almoina, en Valencia (PASCUAL et alii, 2003: 76), así como de ambos tipos en diversos contextos de Tarragona (REMOLÁ, 2000: 54; MACIAS y REMOLÀ, 2005: fig. 6, pza. 9), del Aiguacuit, cerca de Terrassa (SÁNCHEZ et alii, 1989: 151) y de Mataró (CELA y REVILLA, 2004: 227 y 381) con dataciones de entre los siglos VI y VII. En el caso de las cazuelas, las formas más identificativas de este grupo técnico parecen sustituir en el repertorio a las anteriores, pertenecientes principalmente al GT3, y han sido datadas en contexto estratigráfico en torno al siglo IX en Lleida (LORIENTE, 2000: 298) y en Valencia, aunque en este último caso con pequeñas variaciones morfológicas como la presencia de mamelones en lugar de asas, que aparecerán posteriormente en este ámbito geográfico (PASCUAL et alii, 2003: 110). Así, planteamos para este grupo técnico una posible cronología inicial en torno al comienzo del siglo IX, manteniéndose ininterrumpidamente al menos hasta finales del siglo $X$.

\section{GRUPO TÉCNICO 5 (GT5). CERÁMICA DE SERVICIO CON REVESTIMIENTO ARCILLO- SO}

Se trata de un conjunto de piezas conformado principalmente por vasijas para el consumo y el servicio de líquidos y que presentan unas pastas con pequeñas inclusiones micáceas y un revestimiento arcilloso. Se trata de piezas en las que en el proceso de enfriamiento se ha llevado a cabo una aportación de oxígeno, quedando la superficie de las mismas con una tonalidad ocre respecto al gris de su interior. En unos pocos casos incluso se observa una atmosfera completamente oxidante durante todo el proceso de cocción. La gran mayoría de estas piezas carecen de decoración en sus cuerpos, aunque la mayoría de asas presentes en estos recipientes muestran distintos tipos de decoraciones incisas e impresas, posiblemente con la finalidad de mejorar su sujeción. Dentro de este grupo se incluyen, por tanto, los ejemplos más elaborados de cántaros de asas retorcidas y de asas planas con decoraciones combinadas incisasimpresas, a los cuales se les ha proporcionado un revestimiento que podríamos identificar bajo la técnica de esclarecimiento superficial. Los contextos en los que aparecen, además de paralelos localizados en los yacimientos urbanos de la ciudad de Tortosa (CURTO et alii, 1984: 23), nos llevan a proponer para este conglomerado una cronología vinculada a la consolidación de los primeros talleres artesanales urbanos de cierta entidad, posiblemente durante la primera mitad del siglo X, sobreviviendo a la instauración del califato.

\section{GRUPO TÉCNICO 6 (GT6). CERÁMICA FINA DE COCCIÓN OXIDANTE}

Este grupo estaría caracterizado por unas producciones de pastas con moderadas inclusiones micáceas, disminuyendo su número en los contextos más modernos. Se trataría mayoritariamente de jarras relativamente bien torneadas, con decoraciones principalmente estriadas y acanaladas muy sencillas en su cuello. Aunque presenta una factura sencilla y poco estandarizada, su proceso de cocción se lleva a cabo en atmosfera completamente oxidante, para la que se requiere una separación entre la cámara de combustible y la de horneado. Se trata de un grupo que aparece en contextos de diversas cronologías, siendo habitual en aquellos en los que abunda el material decorado típico del califato, pero también en algunos contextos más antiguos, cuyas ocupaciones no parecen superar el siglo X. No obstante, este grupo tipológico no aparece prácticamente nunca asociado a contextos con materiales del GT1 o del GT3, haciéndonos pensar que su aparición no se produciría hasta la consolidación de la ciudad de Tortosa y la aparición de nuevos talleres artesanos más tecnificados, posiblemente a principios del siglo IX. Algunos casos paralelos en la propia ciudad de Tortosa (CURTO et alii, 1984: 14-15 y 23) y en Valencia (PASCUAL et alii, 2003: 


\begin{tabular}{|c|c|c|c|c|c|c|c|}
\hline & Composición & Modelado & Trat. Superficiales & Decoraciones & Revestimientos & Cocción & Cronología \\
\hline $\begin{array}{l}\text { GT1. Cerámica } \\
\text { común de cocción } \\
\text { reductora }\end{array}$ & $\begin{array}{l}\text { - Inclusiones } \\
\text { micáceas y de } \\
\text { cuarcitas }\end{array}$ & $\begin{array}{l}\text { - Manual } \\
\text { - Torno de } \\
\text { rotación irregular }\end{array}$ & $\begin{array}{l}\text { - Alisado } \\
\text { - Raspado }\end{array}$ & $\begin{array}{l}\text { - Estríadas } \\
\text { - Peinadas }\end{array}$ & - Ninguno & $\begin{array}{l}\text { - Reductora } \\
\text { - Enfriamiento } \\
\text { reductor }\end{array}$ & VII - IX \\
\hline $\begin{array}{l}\text { GT2. Cerámica } \\
\text { común decocción } \\
\text { irregular }\end{array}$ & $\begin{array}{l}\text { - Inclusiones } \\
\text { micáceas }\end{array}$ & $\begin{array}{l}\text { - Manual } \\
\text { - Torno de } \\
\text { rotación irregular }\end{array}$ & $\begin{array}{l}\text { - Alisado } \\
\text { - Raspado }\end{array}$ & $\begin{array}{l}\text { - Estriadas } \\
\text { - Peinadas }\end{array}$ & - Ninguno & $\begin{array}{l}\text { - Reductora } \\
\text { - Enfriamiento } \\
\text { irregular }\end{array}$ & VII-IX \\
\hline $\begin{array}{l}\text { GT3. Cerámica } \\
\text { grosera de cocción } \\
\text { irregular }\end{array}$ & $\begin{array}{l}\text { - Abundantes } \\
\text { inclusiones } \\
\text { - Poco depuradas }\end{array}$ & - Manual & - Ninguno & - Ninguna & - Ninguno & $\begin{array}{l}\text { - Reductora } \\
\text { - Enfriamiento } \\
\text { irregular }\end{array}$ & VII - $\mathrm{x}$ \\
\hline $\begin{array}{l}\text { GT4. Cerámica } \\
\text { común de cocción } \\
\text { oxido-reduct ora }\end{array}$ & $\begin{array}{l}\text { - Inclusiones } \\
\text { Micáceas }\end{array}$ & $\begin{array}{l}\text { - Torno de } \\
\text { rotación irregular }\end{array}$ & $\begin{array}{l}\text {-Alisado } \\
\text { - Raspado }\end{array}$ & $\begin{array}{l}\text { - Estriadas } \\
\text { - Peinadas } \\
\text { - Acanaladas } \\
\text { - Punteadas }\end{array}$ & - Ninguno & $\begin{array}{l}\text { - Reductora } \\
\text { - Enfriamiento } \\
\text { oxidante }\end{array}$ & $\mathrm{IX}-\mathrm{x}$ \\
\hline $\begin{array}{l}\text { GTS. Cerámica con } \\
\text { revestimiento } \\
\text { arcilloso }\end{array}$ & $\begin{array}{l}\text { - Escasas } \\
\text { inclusiones } \\
\text { - Micas }\end{array}$ & $\begin{array}{l}\text { - Torno de } \\
\text { rotación irregular } \\
\text { - Torno de } \\
\text { rotación regular }\end{array}$ & - Alisado & $\begin{array}{l}\text { - Acanaladas } \\
\text { - Punteadas }\end{array}$ & $\begin{array}{l}\text {-Arcillosos } \\
\text { - Engobes }\end{array}$ & $\begin{array}{l}\text { - Reductora / } \\
\text { Oxidante } \\
\text { - Enfriamiento } \\
\text { oxidante }\end{array}$ & $\mathrm{x}$ \\
\hline $\begin{array}{l}\text { GT6. Cerámica fina } \\
\text { de cocción oxidante }\end{array}$ & $\begin{array}{l}\text { - Pastas depuradas } \\
\text { - Escasas } \\
\text { inclusiones }\end{array}$ & $\begin{array}{l}\text { - Torno de } \\
\text { rotación regular }\end{array}$ & - Alisado & $\begin{array}{l}\text { - Estriadas } \\
\text { - Acanaladas }\end{array}$ & - Ninguno & $\begin{array}{l}\text { - Oxidante } \\
\text { - Enfriamiento } \\
\text { oxidante }\end{array}$ & $x$ \\
\hline
\end{tabular}

Fig. 2. Clasificación de características técnicas de las producciones cerámicas

113) así parecen confirmarlo.

\section{PROPUESTA DE CLASIFICACIÓN MORFO- FUNCIONAL DE LAS PRODUCCIONES CERÁMICAS}

El estudio morfo-funcional de las producciones cerámicas ha sido tradicionalmente el elemento más representativo en el estudio arqueológico de la sociedad medieval. A pesar de sus limitaciones, estos sistemas básicos de clasificación aún resultan de utilidad para el estudio de las dinámicas históricas de cada territorio y de los propios yacimientos en sí. Para la realización de este apartado hemos tenido en cuenta las características descriptivas básicas de las piezas, como son su base, cuerpo, cuello y borde, que finalmente definen unos tipos morfológicos bien establecidos por la historiografía e incluso por las fuentes documentales medievales (ROSSELLÓ BORDOY, 1978 y 1991; GUTIÉRREZ, 1996). Las referencias a los yacimientos de este territorio tienen su correspondencia en el Anexo 4 de la tesis doctoral de la que se deriva este trabajo (NEGRE, 2013).

El análisis de la forma y la función de las vasijas presentes en el registro cerámico, tanto procedentes de la prospección arqueológica como de los fondos de museo, es un complemento necesario para mejorar la comprensión de la sociedad que los produjo. En muchos casos podría aportarnos información sobre cuáles fueron las necesidades específicas de cada yacimiento, como por ejemplo la escasez de agua reflejada en un incremento de los elementos de contención de líquidos. Cuatro son los grupos funcionales que hemos tratado de distinguir durante este período, en el que el repertorio cerámico es significativamente más reducido que durante la Antigüedad y posteriormente a la instauración del califato: productos destinados a la cocción de los alimentos, a su almacenamiento y transporte; al servicio de mesa y a usos diversos.

\section{Cerámicas para cocción}

Dos son los grupos principales que destacarían entre las cerámicas de cocción: las ollas y las cazuelas. Estas presentan una variabilidad reducida principalmente limitada por su funcionalidad, por lo que su sistematización no está exenta de matices. A pesar de ello trataremos de analizar de forma general la evolución de los tipos que las caracterizan y presentar una primera hipótesis de trabajo.

\section{SERIE OLLA}

Destinadas principalmente a la cocción de alimentos, habitualmente son de forma globular y las formas más tardías tienden a disponer de asas. Es una de las series más presentes en los contextos arqueológicos y habitualmente presentan marcas de ennegrecimiento debidas a su uso. Suelen caracterizarse por una base plana para poder situarse junto al fuego y cocer los alimentos sin más 
soportes adicionales.

\section{Olla1}

Sin cuello ni decoraciones y con el borde exvasado y labio redondeado, en unos pocos ejemplos, recto o biselado. Cuerpo globular muy marcado y de pequeño tamaño, con una boca de entre 10 y $12 \mathrm{~cm}$ de diámetro. Presentan pastas grises reductoras muy características con decoraciones incisas de líneas paralelas, aunque también existen unos pocos ejemplos con pastas rojizas y borde ahumado. Los principales contextos donde se documentan son la propia ciudad de Tortosa (CURTO et alii, 1984: 11), el yacimiento de L'Ermita de l'Aldea (L'Aldea) (RAMS y PÉREZ, 2003), del Mas del Catxorro (Benifallet) (REMOLÀ et alii, 1991), de la Carrova (Amposta) (GARCIA, 2000) y de la Casa Blanca (Tortosa) (REVILLA, 2003). La mayoría de ejemplos documentados se corresponderían con las características del GT1.

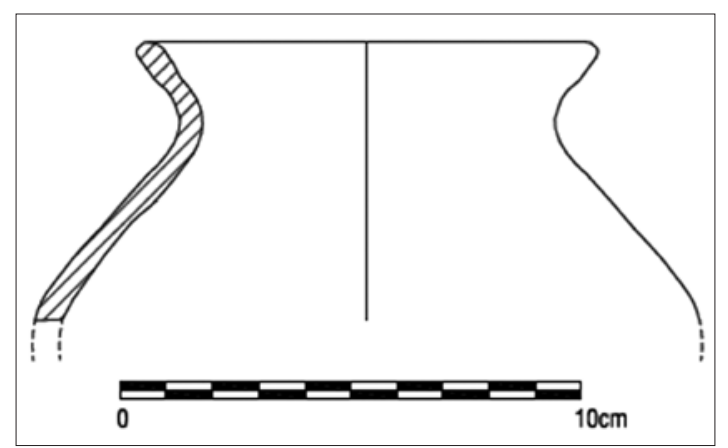

Fig. 3.

\section{Olla2}

De cuerpo globulary perfil poco anguloso, con el cuello ligeramente exvasado y el labio habitualmente biselado o recto. Decorada con incisiones peinadas, estriadas o algunos ejemplos sencillos de acanaladuras. El tamaño es moderado, de base plana y una apertura de entre 12 y $14 \mathrm{~cm}$ de diámetro. Es habitual encontrar piezas con raspado o alisado de su superficie para aligerar y compactar sus paredes. Encontramos ejemplos diversificados a lo largo del territorio de Tortosa, además de en la propia ciudad. Entre ellos pueden destacarse los casos del Pla d'Empúries (Amposta), Lo Molinàs (Amposta), L'Antic (Amposta), Senioles (La Sénia), L'Arion (Ulldecona), Els Masets
(Godall) o Mas del Llop (Alcanar). La mayoría de ejemplos documentados se corresponderían con las características del GT2, y en unos pocos casos, llegan también a apreciarse casos vinculados al GT4, disminuyendo progresivamente su número a medida que aumentan los ejemplos de la OLLA3.

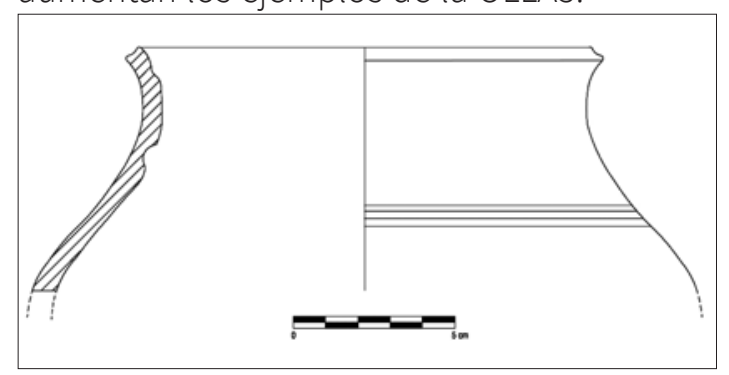

Fig. 4.

\section{Olla3}

De cuerpo globular y cuello hiperbólico más o menos desarrollado, de entre 12-14 $\mathrm{cm}$ de diámetro, presenta una base plana o ligeramente convexa y motivos incisos acanalados a lo largo del cuello, que no siempre llegan hasta el borde. Habitualmente se aprecia un engrosamiento por el interior de la pieza en el punto de unión del cuello con la panza, mostrando abundantes casos de irregularidades en su grosor. Como en el tipo anterior, son abundantes los raspados y alisados de la superficie de la pieza para aligerar su peso. Aparecen documentados en yacimientos como Masets (Godall), Mas del Llop (Alcanar), Mas de la Torre (Ulldecona) o Mas de l'Ermitanyo (Alcanar), entre otros. Sus características más habituales se asociarían al GT2 y al GT4, aunque son mayoritarias las de este último.

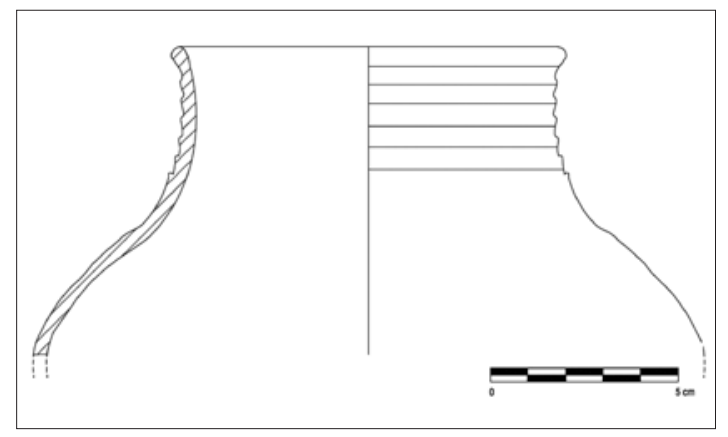

Fig. 5. 


\section{Olla4}

De cuerpo globular muy marcado y base completamente plana, con el cuello cilíndrico y decorado con acanaladuras cada vez más definidas, con un labio de sección habitualmente triangular. Presenta dos asas planas de pequeñas dimensiones entre la curvatura de su cuerpo y el cuello, habitualmente decoradas con estrías o bandas paralelas. Se documenta de forma extensa en los yacimientos como Arenalets (Xerta), L'Assut (Tivenys) o el Pla d'Empúries (Amposta), y en el ámbito urbano y castral, tanto en Tortosa como en Amposta. Sus características técnicas

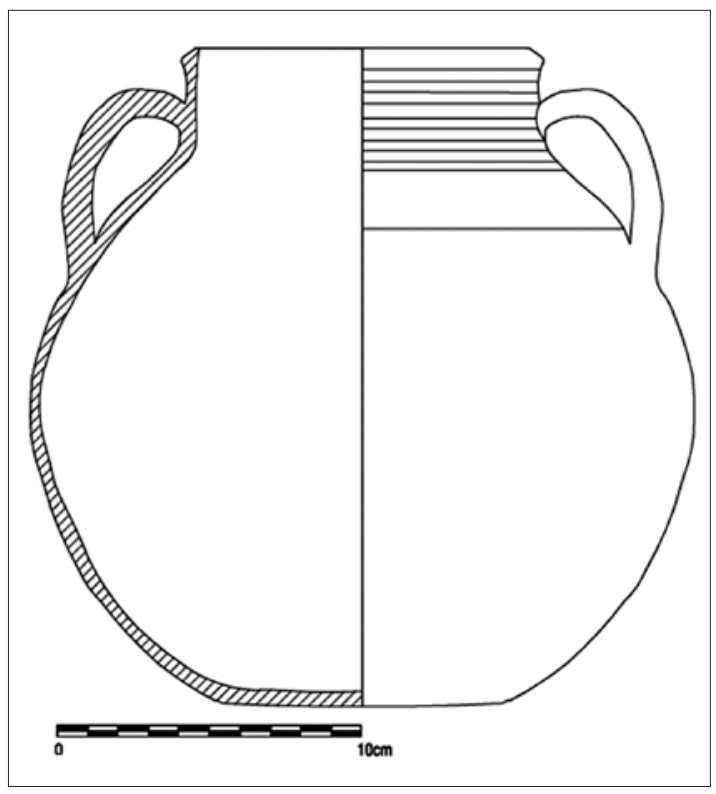

se corresponderían ampliamente con el GT4.

Fig. 6.

\section{SERIE CAZUELA}

Las tres formas representativas de esta serie presentan una base plana y abundantes inclusiones de medidas considerables, con el fin de facilitar su uso para la cocción de alimentos y evitar su ruptura o agrietamiento.

\section{Cazuela1 (Fig. 7)}

De perfil hemisférico, base convexa y labio almendrado reentrante, esta forma se caracteriza por la ausencia de decoraciones y unos acabados relativamente buenos. Su presencia es anecdótica fuera de ciertos ámbitos concretos, como el Castillo de Amposta o la propia ciudad de Tortosa. Sus características las encuadrarían dentro del GT3, careciendo de decoraciones y con inclusiones de tamaño considerable, que permiten observar diversas vacuolas en su superficie.

\section{Cazuela2 (Fig. 8)}

De forma circular, base plana, paredes verticales y labio redondeado, este tipo se caracteriza por una producción muy simple realizada preferentemente a mano, siendo su característica más destacada la presencia de dos asas tubulares horizontales adheridas a las paredes de la misma. Aparece de forma significativa en yacimientos como L'Arion (Ulldecona), Senioles (La Sénia), Molinàs (Amposta) o el propio Castillo de Amposta. Sus características técnicas las situarían dentro del GT3,

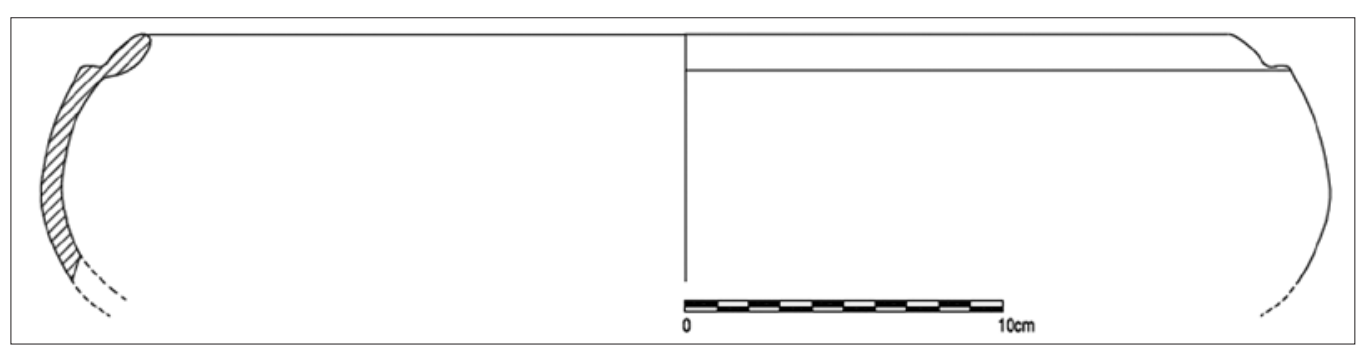

Fig. 7.

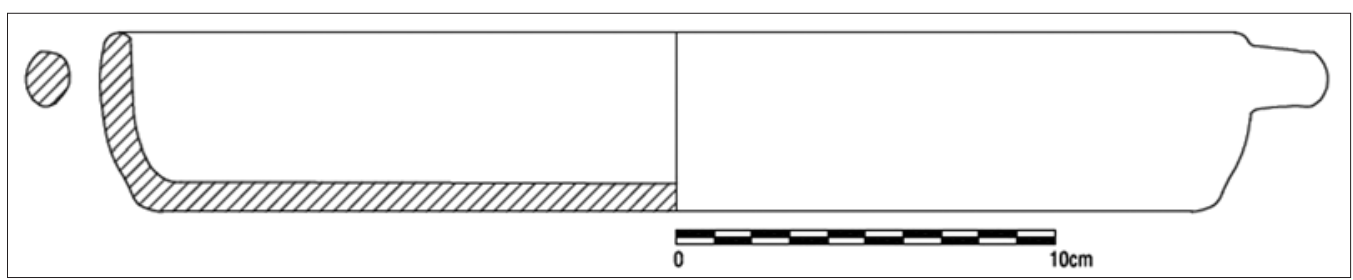

Fig. 8. 
al igual que el tipo anterior.

\section{Cazuela3 (Fig. 9)}

Se trata de un conjunto de recipientes mayoritariamente de forma oval, de poca altura, con base plana, paredes abiertas ligeramente entrantes, boca amplia y labio redondeando, generalmente con mamelones o dos pequeñas asas planas en sus extremos distales. La altura de estas piezas oscila entre 5 y 7 cm y técnicamente están realizadas en dos pasos, disponiendo primero la base y elevando a continuación las paredes. De ello resultan piezas de aspecto notablemente tosco, en las que se suelen advertir con claridad huellas de dedos resultantes de la presión ejercida sobre la arcilla para unir las dos partes. Se trata de un tipo que pertenecería en su totalidad al GT4, aunque como diferencia principal se observan unas inclusiones calizas abundantes, así como numerosas vacuolas y se puede advertir la aplicación de un cierto alisado para disimular las marcas de manufactura. Se han detectado ejemplos claros de estas producciones en el Castillo de Amposta, en el Pla d’Empúries (Amposta), en el Molinàs (Ampos- ta), así como en la propia ciudad de Tortosa.

\section{Cerámicas para la contención, almacenamiento y transporte}

Se trata de un conjunto de series caracterizadas por su función de almacenamiento y transporte de productos, tanto sólidos como líquidos. En el caso de los cereales, parece ser que su uso fue menos extendido que en otras zonas por la continuidad del sistema de silos excavados en la roca, como se ha podido documentar en numerosos yacimientos (NEGRE y MARTí, 2013).

\section{SERIE CÁNTARO}

Esta serie se caracterizaría por grandes contenedores de líquidos destinados al almacenamiento y/o transporte de los mismos, recogiendo el testimonio de las desaparecidas ánforas pero para ámbitos de distribución mucho menores. A diferencia de las jarras, su funcionalidad para el servicio de mesa debió ser muy reducida.

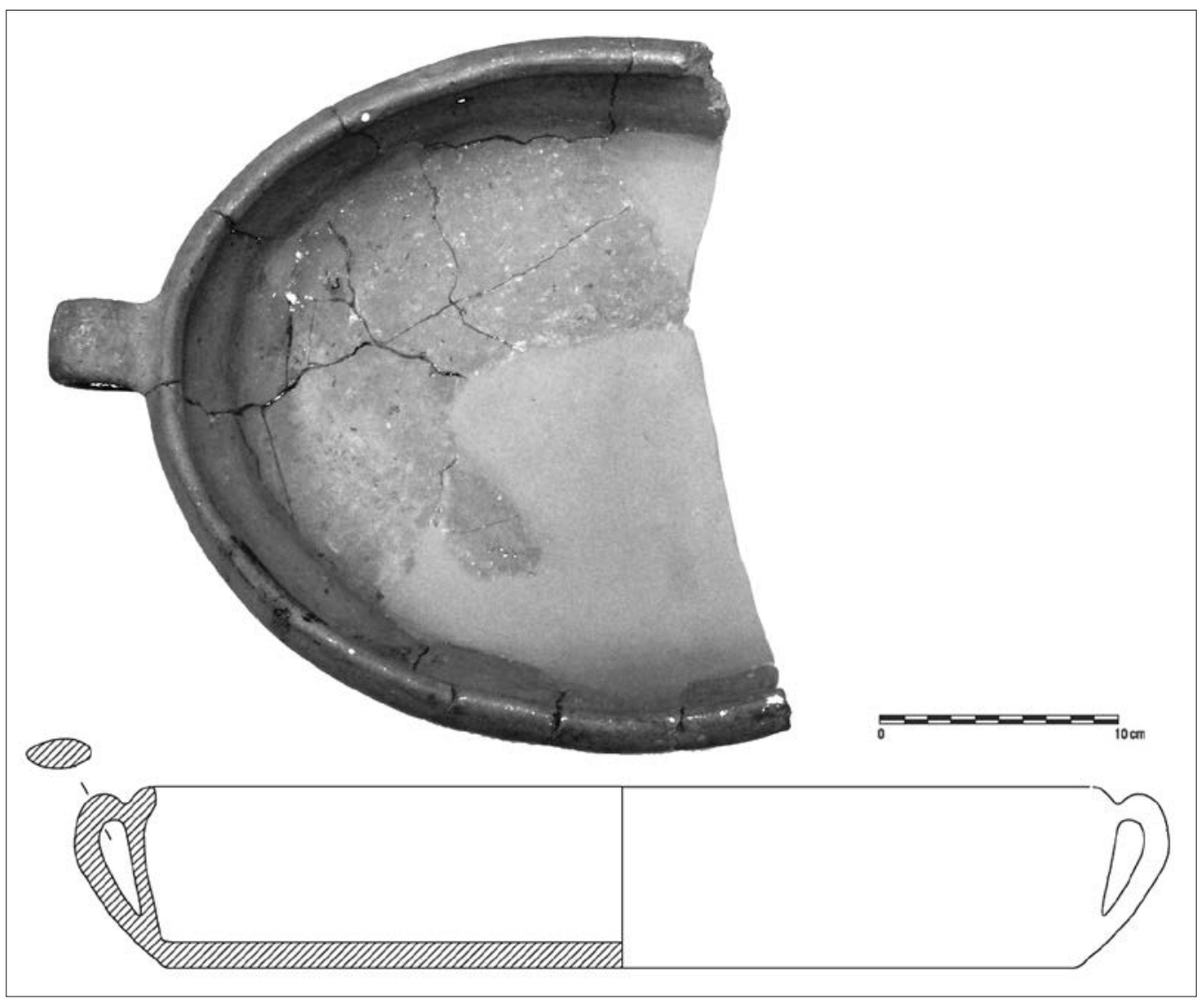

Fig. 9. 


\section{Cántaro1 (Fig. 10)}

Tipo caracterizado por un cuerpo globular más o menos estilizado y de gran tamaño, con base plana y cuello cilíndrico de unos $10 \mathrm{~cm}$ de diámetro decorado en la mayoría de casos con incisiones acanaladas. Dispone de dos asas tubulares que conectan el cuello y el cuerpo de forma prácticamente circular, decoradas con incisiones helicoidales. Se trata de una tipología con una distribución circunscrita al territorio de Tortosa, apareciendo ejemplos de la misma en yacimientos de comarcas castellonenses y por el norte en gran parte de la Ribera de l'Ebre. Se documentan en la práctica mayoría de yacimientos estudiados del ámbito tortosino, presentando dos principales variantes. Una primera, vinculada al GT4 de características técnicas, y otra, caracterizada técnicamente por el GT5, es decir, con presencia de revestimiento arcilloso a modo de esclarecimiento superficial.

Cántaro2 (Fig. 11)

De forma globular, con cuello cilíndrico de aproximadamente $8-10 \mathrm{~cm}$ de diámetro y base cóncava-convexa a juzgar por algunos ejemplos identificados pero sin conexión con el resto del cuerpo de la pieza. Se trata de una pieza de grandes dimensiones caracterizada por unas marcas de torneado y de unión a modo de sutiles bandas paralelas. Dispone de dos asas planas de tamaño considerable que unen el extremo del cuello con el cuerpo de la vasija, decoradas en la mayoría de casos con incisiones y punteados de forma combinada. Igual que sucedía con el tipo anterior, este grupo de cántaros de presencia abundante en la práctica totalidad de yacimientos, presentaría dos variantes principales: una primera vinculada al GT4 de características técnicas y otra, asociada al GT5, con revestimiento arcilloso.

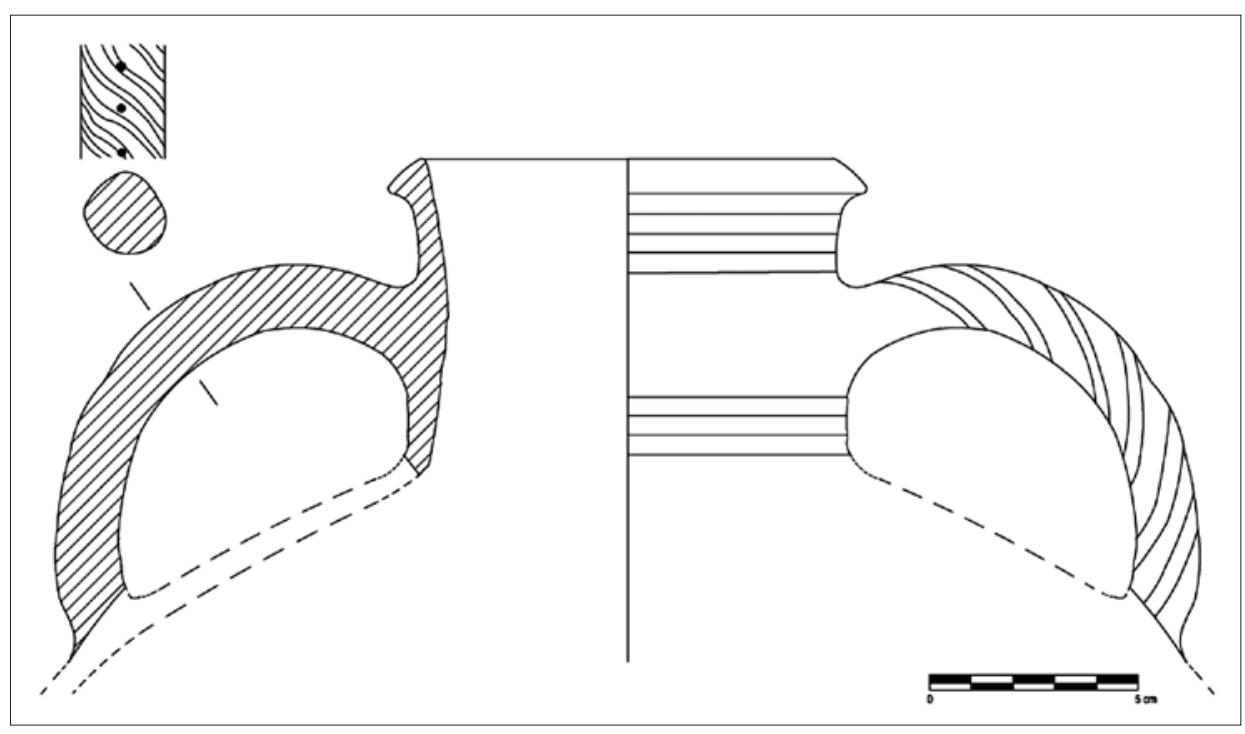

Fig. 10.

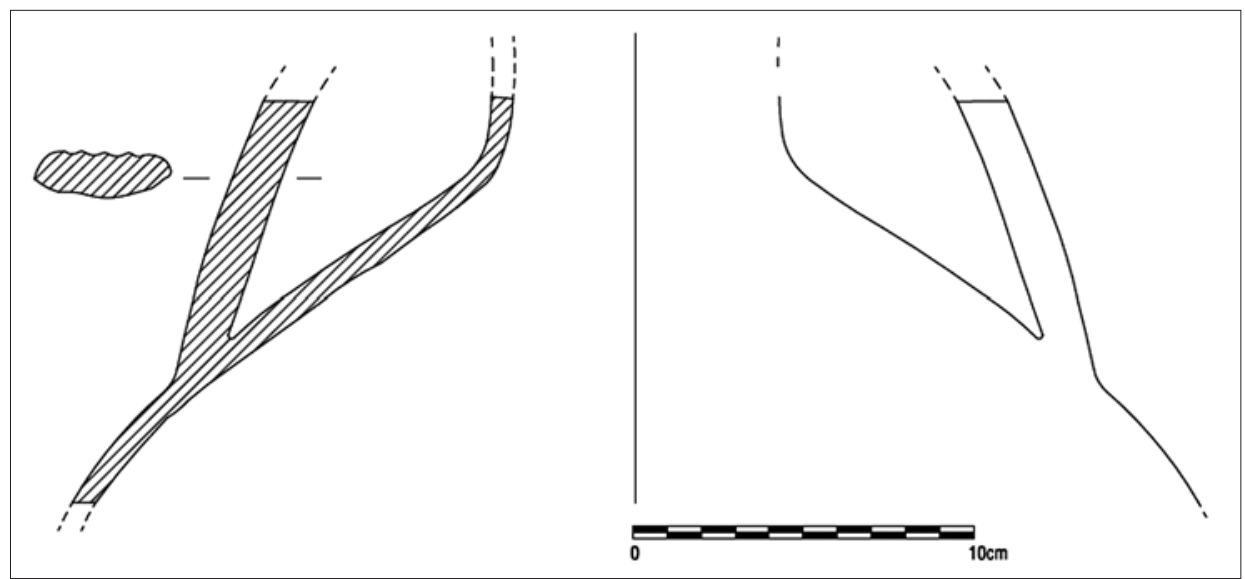

Fig. 11. 


\section{SERIE TINAJA}

Guardan ciertos paralelismos con los dolia romanos y habitualmente disponen de encaje para tapadera para evitar el contacto de su contenido con el aire y los agentes externos, aunque al tratarse en muchos casos de elementos realizados con materiales perecederos como la madera no han dejado testimonios de su existencia.

\section{Tinaja1 (Fig. 12)}

Contenedor de grandes dimensiones, de cuerpo ovoide y cuello cilíndrico, con el labio engrosado, de sección triangular y un diámetro de aproximadamente $26 \mathrm{~cm}$. Presenta decoraciones habitualmente de cordones con digitaciones en su carena, y en algunos casos se documenta la presencia de asas planas con una acanaladura en el centro que conectan el cuello con la parte alta del cuerpo. La poca abundancia de este tipo en el registro así como su extrema fragmentación, sin embargo, no nos permite presentar un perfil completo del mismo. Se trata de piezas con un espesor grueso de sus paredes, de más de 1 centímetro, y en su totalidad se corresponderían con el conjunto de observaciones características del GT3, con diversas inclusiones calizas, chamota de gran tamaño y vacuolas abundantes. Se documentan ejemplos de este tipo en los yacimientos del Ligallo de les Veles (L'Aldea), Mas de Xies (Tortosa), L'Arion (Ulldecona), Mitjà de Cavil.la (Mas de Barberans) y L'Ermita (Ulldecona).

\section{Cerámicas para el servicio de mesa}

Este conjunto de series está representado por las producciones cerámicas destinadas al servicio de alimentos y a los recipientes usados para su consumo. Se trata por tanto de un grupo diversificado que responde a las necesidades básicas de la vajilla de mesa, por lo que la variabilidad de sus formas es bastante elevada.

\section{SERIE JARRA}

Este tipo de vasijas está destinado al servicio de líquidos en mesa y a su contención temporal. Con una o dos asas, presentan un tamaño mediano que facilita su transporte y manipulación durante su uso. Esta serie, al contrario de la propuesta de Roselló-Bordoy (1978: 29, 31, 40), dispone indistintamente de una o dos asas, definiéndose más por su funcionalidad de servicio que por una morfología clara.

\section{Jarra1 (Fig. 13)}

Muy similar al tipo OLLA3, estas jarras presenta una base ligeramente convexa, cuerpo globular y cuello hiperbólico más o menos desarrollado. En algunos casos estas piezas pueden presentar decoraciones con estrías o acanaladuras que no siempre llegan hasta el borde. Como diferencia principal respecto al tipo destinado a cocción, estas piezas disponen de una o dos asas y en algunos casos podrían disponer de pico vertedor de pellizco. Se caracterizan por pertenecer a los conjuntos técnicos representados por el GT2. Se documentan fragmentos de este tipo en el Pla d'Empúries (Amposta), L'Arion (Ulldecona), l'Ermita (Ulldecona), Senioles (La Sénia) y el

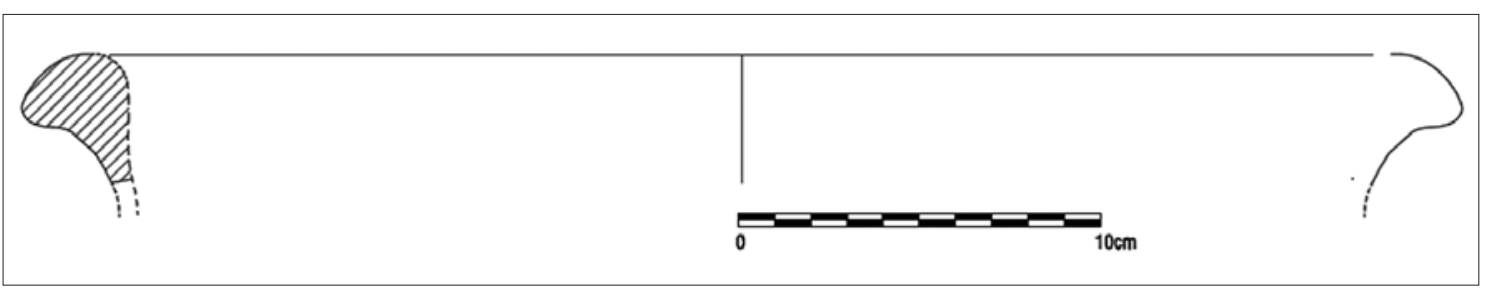

Fig. 12. 


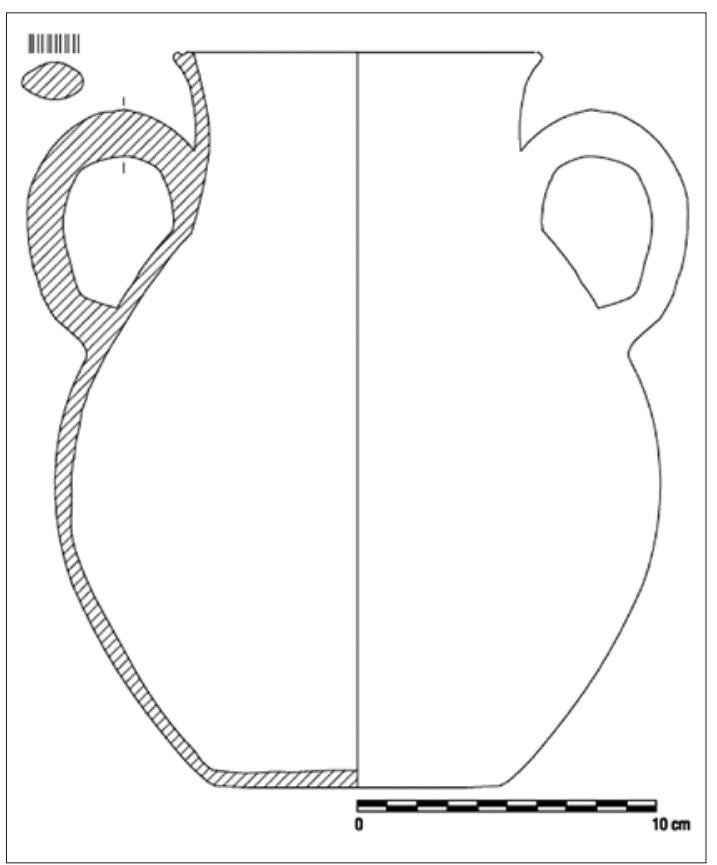

Mas del Llop (Alcanar), entre otros.

Fig. 13.

Jarra2 (Fig. 14)

Jarra de cuerpo globular y base plana, ligeramente convexa, de cuello troncocónico invertido y un labio redondeado de entre 8 y $10 \mathrm{~cm}$ de diámetro, posiblemente con pico vertedero. Dispone de un asa tubular entre

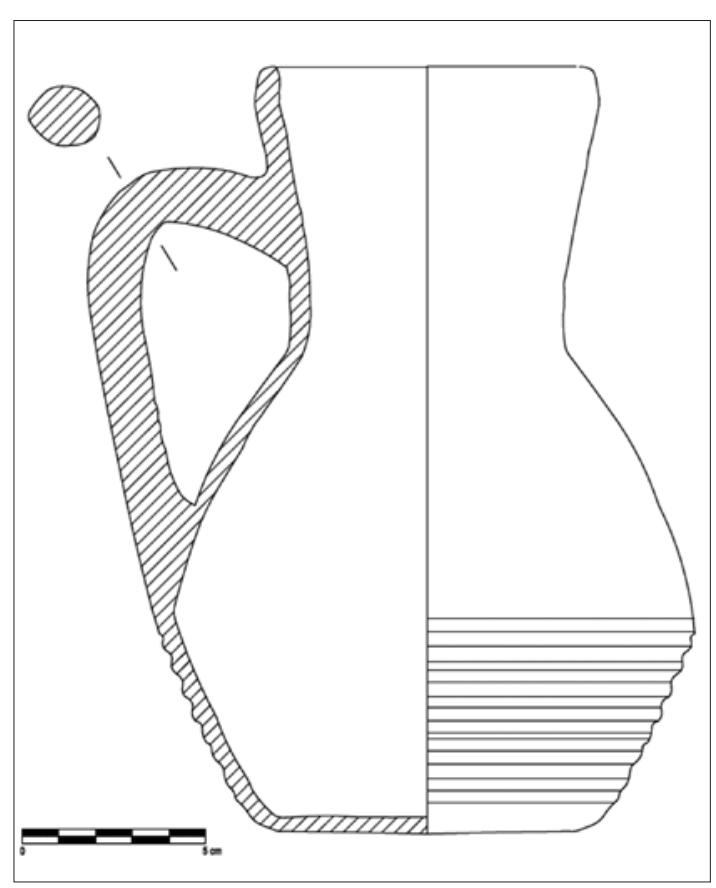

Fig. 14. el cuello y el cuerpo para permitir su uso, y está decorada con bandas incisas en la mitad inferior de la pieza. Principalmente se trata de un tipo caracterizado por piezas posiblemente del GT4, aún con abundantes inclusiones intencionadas y un modelado muy irregular. Se ha detectado un ejemplar prácticamente completo en la Carrova (Amposta) y fragmentos de diversa consideración en yacimientos como el Molinàs (Amposta), Pla d'Empúries (Amposta) o el Molí Nou (Ulldecona).

\section{Jarra3 (Fig. 15)}

Tipo caracterizado por vasijas de cuerpo globular y base plana, con un cuello cilíndrico ligeramente exvasado de unos $12 \mathrm{~cm}$ de diámetro y labio redondeado. Dispone de una asa de sección rectangular con dos bandas incisas a lo largo de la misma, además de contar con decoración incisa peinada en la parte superior de la pieza, en algunos casos con acanaladuras. Técnicamente podrían vincularse al GT5 y al GT6, presentando en algunas ocasiones una variante más tardía con las características técnicas de este último pero con el revestimiento arcilloso que caracteriza al primero. Aparece en el registro del Castillo de Amposta, el Molinàs (Amposta) y Arenalets (Xerta), entre otros.

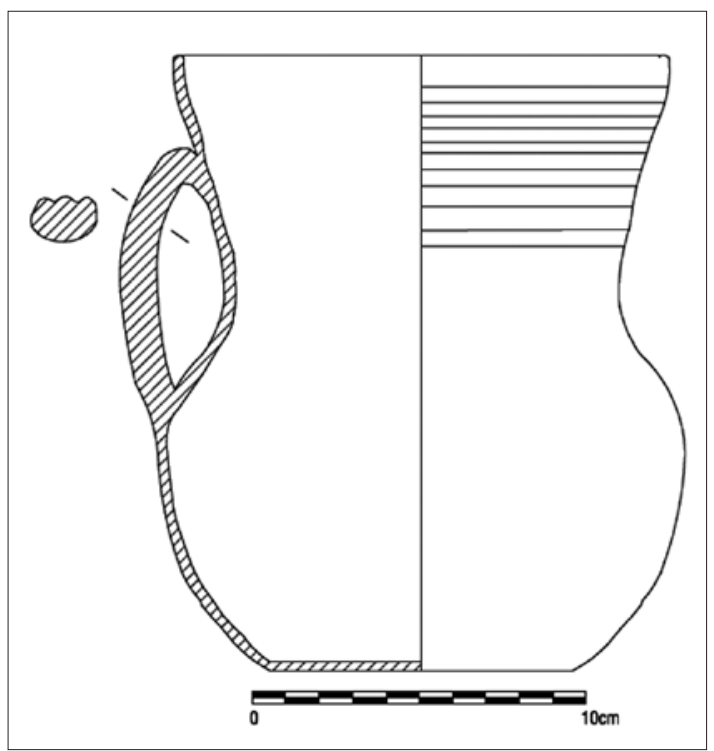

Fig. 15. 


\section{SERIE JARRITO}

Se trata de una serie que conforma el principal elemento para el consumo de líquidos durante toda la Alta Edad Media en al-Andalus, siendo uno de los elementos más característicos de los contextos emirales. Con una única asa y de tamaño reducido, encontramos algunos modelos iniciales que probablemente mantengan una tradición tardo-antigua de abandonamiento de las formas de tipo bol en favor de estas vasijas. La forma más habitual durante el emirato dispone de cuerpo globular y cuello vertical ligeramente exvasado.

\section{Jarrito1 (Fig. 16)}

De cuerpo globular con el cuello ligeramente exvasado, este tipo presenta además un labio ligeramente redondeado y con una única asa que presenta continuidad respecto a este último. De base plana y tamaño reducido, su boca no suele superar los $10 \mathrm{~cm}$ de diámetro, perteneciendo probablemente la mayoría de casos documentados al GT1 y al GT2 de nuestra clasificación productiva. Encontramos ejemplos de este tipo en los yacimientos del Bancal de Torta (Amposta) y la Carrova (Amposta), este último destruido junto con su necrópolis por la construcción de una cantera.

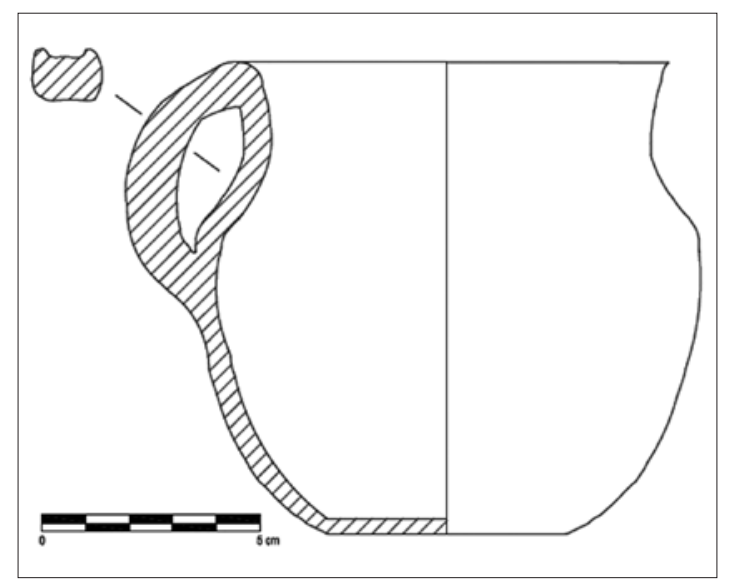

Fig. 16.

\section{Jarrito2 (Fig. 17)}

Se trata de una de las tipologías de cerámica común más representativa en el registro emiral, caracterizada por una base plana, cuer- po globular y cuello cilíndrico desarrolla, con una pequeña asa entre cuello y cuerpo. Tanto el cuello como el asa presentarían decoraciones incisas peinadas. El labio es redondeado o de sección triangular y contaría con decoraciones estriadas o acanaladas en la parte superior de la pieza. Se han detectado piezas de este grupo en los yacimientos de la Cova del Aire (La Sénia), la Carrova (Amposta), el Molí Nou (Ulldecona) y el Castillo de Amposta. En general, el tipo respondería a unas características bien descritas por el GT2 y el GT4.

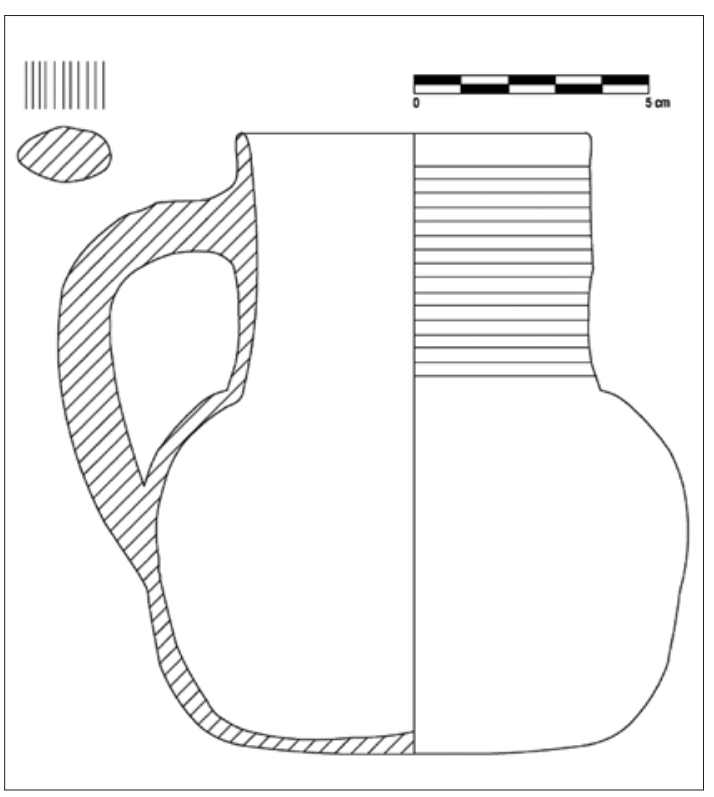

Fig. 17.

\section{Cerámicas para usos diversos}

\section{SERIE BARREÑO}

Elemento poli-funcional de grandes dimensiones. El único ejemplo de que disponemos presenta unos acabados muy sencillos, y por su elevada altura parece haber estado destinado a la colada, las abluciones o la higiene personal.

\section{Barreño1 (Fig. 18)}

Tipo caracterizado por un único individuo, procedente del yacimiento del Pla d'Empúries (Amposta). Se trata de un recipiente de gran tamaño, una altura de medio metro y un diámetro superior de más de $40 \mathrm{~cm}$, con unas 
gruesas paredes de aproximadamente 1,5 $\mathrm{cm}$ de espesor. De borde plano con engrosamiento y con decoración ungulada y digitada a lo largo del mismo, presenta una forma troncocónica invertida y una manufactura manual o a torneta, con abundantes marcas de modelado. Técnicamente pertenecerían al GT3, aunque presentan un tratamiento superficial de alisado que le da un característico tono brillante y una mayor impermeabilidad. Su uso como barreño para la colada o para abluciones e higiene personal, requeriría de este tipo de solución técnica con el fin de evitar posibles pérdidas de líquidos y roturas por desgaste.

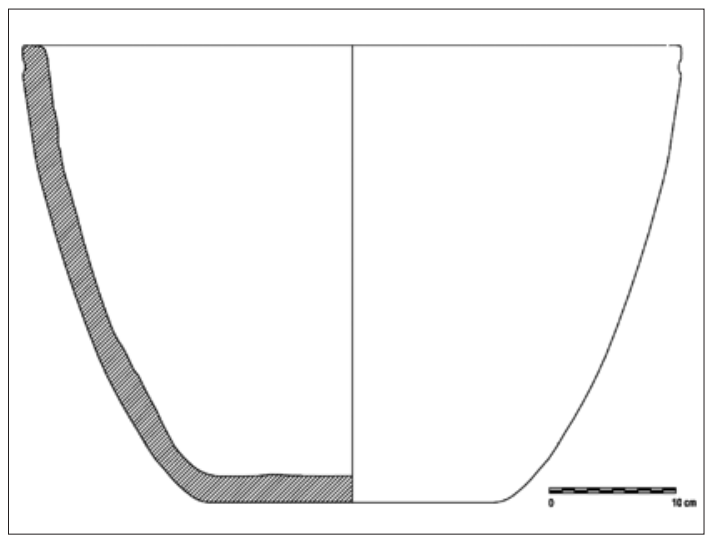

Fig. 18.

\section{UN PRIMER ANÁLISIS INTERPRETATIVO}

Cabe recordar que las producciones cerámicas hasta ahora presentadas son el resultado del estudio minucioso de unos contextos procedentes de prospecciones arqueológicas y de fondos de museo, la mayoría sin ninguna relación estratigráfica ni dataciones absolutas. Es esta, por tanto, una propuesta de trabajo, una primera aproximación tipológica a partir de la cual esperamos facilitar el estudio del registro cerámico de este ámbito regional concreto. Solo a partir de futuras intervenciones arqueológicas, ya programadas, y con la detallada documentación de las estratigrafías de estos yacimientos, se podrán matizar o modificar estas primeras reflexiones genéricas. Analicemos, pues, de forma sistemática las diferentes series morfo-funcionales propuestas, a partir de su análisis cruzado con los grupos productivos establecidos y los ejemplos de excavaciones cercanas que puedan presentar materiales de características similares.

La primera de las series bajo análisis, las ollas, parece presentar unas características que definen con precisión su evolución, manteniendo un cuerpo globular y tendiendo progresivamente hacia la verticalidad de su cuello con borde exvasado. Categorizadas desde hace décadas como ollas valencianas (BAZZANA, 1986 y 1990), el actual nivel de conocimiento respecto a su distribución real, más allá de territorios hoy valencianos, nos obliga a plantear una nueva definición más precisa, quizás como ollas levantinas. Los tipos más antiguos de esta serie presentan paralelos por ejemplo en la excavación de la Plaça de l'Olivera, en la ciudad de Tortosa, donde observan estas piezas en los contextos que atribuyen a finales del siglo VII y principios del VIII (CURTO et alii, 1984: 11). Por tanto, la cronología de los tipos OLLA1 y OLLA2, en base a estos datos, creemos que podría fijarse de forma provisional entre los siglos VI-VII y VII-IX, respectivamente.

En los tipos más modernos de esta serie, como la OLLA3, los bordes tienden a formas más redondeadas, desarrollándose además el cuello y las decoraciones acanaladas en el mismo. La ausencia de asas parece ser generalizada hasta el siglo $X$, momento en el cual podemos observar los primeros ejemplos pertenecientes al tipo OLLA4. Los motivos decorativos más habituales serían las incisiones estriadas o peinadas en el cuello de las piezas en un primer momento, dando lugar a motivos acanalados cada vez más definidos y estilizados en los últimos modelos productivos, netamente visibles en el tipo OLLA4. Ambos grupos presentarían, por tanto, características técnicas bien definidas por el GT4 de nuestro trabajo, y cuentan con paralelos muy claros en contextos excavados de la ciudad de Tortosa (CURTO et alii, 1984: 14-15), así como en Valencia, aunque con ligeras variaciones en cuanto a su cocción, reductora en el caso meridional, y un perfil ligeramente diferente para el último tipo (PASCUAL et alii, 2003: 108-110). 
Es habitual la presencia de marcas de ennegrecimiento por su uso en el fuego para calentar o cocer los alimentos, aunque no puede obviarse una funcionalidad secundaria de contención para la serie entera. La sencillez de las formas productivas anteriores al califato, así como la limitada amplitud del repertorio cerámico, es visible dentro de este grupo de piezas que pueden presentar en algunos casos funciones similares a las de las jarras, distinguibles en este caso por la presencia habitual de asas en estas últimas, así como por un diámetro de apertura de la boca del recipiente ligeramente inferior al de las ollas. En este caso serían también las marcas de ennegrecimiento por su uso para cocción las que pueden ayudar a distinguir ambas series, aun a pesar de que la polifuncionalidad de las mismas no es descartable. Únicamente en fechas posteriores, a partir del período taifa, se documentan en nuestro registro nuevos tipos de ollas en las que aparece por vez primera la presencia de un vidriado interno, una tendencia también apuntada para la propia ciudad de Tortosa (CURTO et alii, 1984: 42).

Las cazuelas son otro de los grupos más representativos en los contextos emirales, junto con las ollas que acabamos de analizar. Estas formas tendrían una larga tradición en el conjunto de la vajilla funcional de cocina, y podemos encontrarlas presentes en la mayoría de contextos tardo-antiguos. En el caso de las producciones tortosinas, parece que la forma más antigua documentada sería la del tipo CAZUELA1. Parece tratarse, en este caso, de un tipo de similares características morfológicas a las cazuelas FCW casserole 12, mayoritarias en los contextos de segunda mitad del siglo VI en la ciudad de Valencia (PASCUAL et alii, 2003: 96), y que las importaciones de Lipari de mediados de esta misma centuria aparecidas en diversos contextos de la ciudad de Tarragona (MACIAS y REMOLÀ, 2005: fig. 5, pza. 3). Se trataría, pues, de un tipo productivo que recoge este testigo y mantiene unos modelos funcionales anteriores, a escala de producción y distribución regional, durante los siglos VII y VIII.

Otro grupo de clara influencia tardo-antigua es el definido por el tipo CAZUELA2, de las que dispondríamos de paralelos morfológicos similares en las producciones de la ciudad de Tarragona de segunda mitad del siglo VII, acompañando a producciones importadas de Late Roman and Byzantine cooking ware 3 y Grey gritty ware (MACIAS y REMOLÀ, 2005: 129). La cronología de aparición de esta producción local se integraría entre finales del siglo VII y principios del VIII, completando junto con el tipo anterior las cazuelas vinculadas al GT3. Aunque estos dos tipos perviven de forma sistemática en los contextos islámicos de Tortosa, a partir del siglo IX comenzaría a aparecer uno nuevo, caracterizado por el grupo CAZUELA3 e identificado fácilmente por su base ovoide, que acabaría por sustituirlas. Sus pastas suelen ser de un color ocre en su superficie pero con un grueso núcleo grisáceo, contando con pequeñas asas o mamelones en sus extremos distales y abundantes inclusiones calizas y micáceas, características que la encuadran probablemente dentro del GT4.

Disponemos de diversos paralelos tanto en excavaciones de la próxima ciudad de Lleida (LORIENTE, 2000: 298) como de Valencia, este último con mamelones en lugar de asas (PASCUAL et alii, 2003: 110), cuyos autores ratifican esta propuesta cronológica. Cabe destacar, sin embargo, que en los contextos de esta última ciudad, la versión de este tipo de cazuela con asas en lugar de mamelones se identifica a partir del siglo XI en yacimientos como la de Banys de València (SOLER 1988: 49), considerándose una evolución del tipo anterior. Los contextos más septentrionales, sin embargo, parecen indicar una aparición más temprana de este tipo de asas en este grupo de cazuelas en concreto.

En cuanto a las cerámicas destinadas al almacenamiento y transporte, la primera serie sobre la que hemos podido trabajar son los cántaros, grandes recipientes destinados a la contención de líquidos que recogerían la antigua tradición anfórica, como veremos. Esta continuidad podría observarse al analizar el tipo CÁNTARO1, que describe un conjunto de piezas de gran tamaño, de cuerpo globular, base plana y asas con decoraciones incisas helicoidales, habitualmente llamadas asas 
retorcidas por su apariencia similar a la de una soga retorcida. Se trata de un producto que presentaría notables similitudes con ciertos materiales aparecidos en Mataró (CELAy REVILLA, 2004: 227 y 381), en el yacimiento del Aiguacuit en Terrassa (SÁNCHEZ et alii, 1989: 151) y en Tarragona (MACIAS y REMOLÀ, 2005: fig. 6, pza. 9) e identificados como materiales comunes importados del norte de África. Observamos en nuestros contextos piezas vinculadas a producciones del siglo IX con pastas color rosado exterior y núcleo gris, con inclusiones micáceas abundantes y sin ningún tipo de revestimiento superficial, vinculadas habitualmente al GT4.

Su área de distribución es bastante amplia, pero no parece sobrepasar las fronteras del territorio de Tortosa o zonas muy cercanas, documentándose los más lejanos ejemplos en un testar cerca del actual municipio de Onda, en la provincia de Castellón (MONTMESSIN, 1980: 273). En diversos yacimientos, como el castillo de Amposta o la propia ciudad de Tortosa (CURTO et alii, 1984: 23), hemos podido además identificar producciones más modernas con características propias del GT5, con un esclarecimiento de su superficie de color blanquecino, tanto a nivel interno como externo. En los casos más tardíos, como los localizados en nuestro territorio en el Castillo de Miravet, se pueden identificar ejemplos que además del revestimiento presentan decoraciones con trazos pintados en su superficie, cuya distribución llega hasta la ciudad de Valencia (BAZZANA, 1990: 152) y que perviven en contextos de época almohade, según estudios aún inéditos realizados en el yacimiento de la Almoina.

Dentro de este mismo grupo funcional, encontramos el tipo CÁNTARO2, que presenta una evolución igualmente amplia y compleja. Estos contenedores estarían caracterizados principalmente por dos asas planas de grandes dimensiones situadas en los laterales de un cuerpo ligeramente globular, y que en muchos casos estarían decoradas con incisiones y punteados impresos, quizás para mejorar su sujeción. Los recipientes de este grupo parecen presentar muchas características similares a las de las ánforas tardo-antiguas presentes en los contextos de amortización de unos pozos del yacimiento de l'Almoina (Valencia), datados entre finales del siglo VI e inicios del VII (PASCUAL et alii, 2003: 76). Se trata de vasijas pertenecientes a un tipo de ánforas de tamaño reducido con un característico fondo cóncavo-convexo, similares a las formas Keay LXXII, presentes también en el yacimiento de la Antiga Audiència de Tarragona (REMOLÁ, 2000: 54). Aunque las producciones de ambos tipos de cántaros parecen adaptarse a modelos productivos vinculados ya al siglo IX, principalmente caracterizados por el GT4, la relación entre estas producciones y las tardo-antiguas, que podrían haber pervivido de forma residual durante el siglo VIII, es innegable. Al igual que en el grupo anterior, parece existir una variante de esta producción con revestimiento arcilloso blanco en toda su superficie que se vincula a las características productivas del GT5 y a una cronología inicial de primera mitad del siglo $X$, tal y como lo corroborarían los contextos estratigráficos de la ciudad de Tortosa (CURTO et alii, 1984: 23).

Las tinajas conforman el otro grupo de contenedores y recipientes de almacenaje de alimentos documentado en los contextos arqueológicos estudiados. El único tipo establecido, TINAJA1, con características propias del GT3 y del GT4, está muy poco representado en el registro. Su cronología es bastante diversificada dentro de los contextos analizados, algunos de ellos de clara adscripción emiral y sin continuidad durante el califato. Aunque su cronología es amplia, los contextos en los que ha sido documentado este tipo, así como los paralelos cercanos en la ciudad de Valencia (PASCUAL et alii, 2003: 110) y en el yacimiento del Zambo (Novelda) (GUTIÉRREZ, 1996: 89), nos hacen proponer su aparición en este ámbito durante la segunda mitad del siglo IX. La escasez detectada puede estar relacionada con la presencia masiva en la práctica mayoría de yacimientos de silos para el almacenamiento de cereales, una función que supliría la necesidad de producir este tipo de contenedores.

Así llegamos al grupo de materiales que responderían a una funcionalidad de servicio de mesa, es decir, a la contención de alimentos y líquidos para su consumo. La primera 
serie a destacar dentro de este conjunto sería la conformada por las diversas jarras destinadas al almacenamiento temporal de líquidos y a su distribución. Entre estas podemos distinguir una primera tipología conformada por el tipo JARRA1, con una morfología muy similar a la de las ollas del tipo OLLA3 pero con el cuello más estrecho y vertical. Se trataría de piezas que presentan pastas muy porosas y con presencia de micas entre sus inclusiones, con cocciones reductoras en su interior y un enfriamiento irregular con aporte intermitente de oxígeno, características propias del GT2.

En este caso también encontramos paralelos morfológicos muy similares en el conjunto de cerámicas comunes tardo-antiguas de la ciudad de Tarragona, aunque en la mayoría de casos son considerados como ollas (MACIAS y REMOLÀ, 2000: 492) y del ámbito rural de la ciudad de Tortosa, como en el yacimiento del Mas del Catxorro (Benifallet) (REMOLÀ et alii, 1991: 78). Esta producción, por tanto, parece que sería la mayoritaria durante el primer período de ocupación del levante peninsular en época islámica, tal y como parecen corroborarlo también otras intervenciones arqueológicas realizadas en este ámbito geográfico (MARTí y SELMA, 1997: 1391), por lo que nos decantamos hacia una cronología de entre los siglos VII-VIII para su origen. Aunque en contextos del siglo IX, los ejemplos de la ciudad de Valencia parecen reproducir este mismo esquema ambivalente entre olla y jarra en los primeros niveles bien datados de cronología islámica (PASCUAL et alii, 2003: 108-110), unos tipos que podrían mostrar una cierta continuidad respecto al siglo anterior.

El segundo tipo de jarras identificado, JARRA2, presenta paralelos claros en la ciudad de Lleida, también con pastas bastas con abundantes inclusiones no intencionales y una cocción en atmósfera oxidante (LORIENTE, 2000: 297). El momento inicial de estas producciones, vinculadas principalmente al GT4, pensamos que podría establecerse en algún momento del siglo IX, vinculado a la aparición de nuevos talleres urbanos más tecnificados y que consolidarían la especialización regional de estas producciones. Junto con esta tipología se presentaría un segundo tipo de cronología y producción similar, la JARRA3, de cuerpo globular y cuello ligeramente exvasado, marcas de torneado evidentes, labio redondeado con vertedera opuesta a su única asa, caracterizada en muchos casos por un acanalado central. Se trataría de una tipología que responde a unas características técnicas más desarrolladas, propias del GT6, con procesos de cocción en atmosfera completamente oxidante, y que probablemente perviviría a la instauración del califato.

En contraposición a esta serie vinculada principalmente al servicio, disponemos de numerosos ejemplos de piezas destinadas al consumo de líquidos, como los representados por la serie de jarritos. Estos, dotados con una única asa y de tamaño reducido, se podrían haber desarrollado para la sustitución progresiva del bol tardo-antiguo. La primera de las tipologías que hemos propuesto, el tipo JARRITO1, con abundantes inclusiones micáceas y una cocción en atmósfera reductora, características propias del GT1. Encontramos paralelos similares a este tipo en contextos del sudeste peninsular (GUTIÉRREZ, 1996: 91) y del área catalana (NOLLA y CASAS, 1997) ya desde el siglo VI. La segunda de las tipologías que hemos podido detectar en los contextos tortosinos está incluida dentro del tipo JARRITO2, con decoraciones habituales incisas estriadas, peinadas o acanaladas, y ubicadas siempre en la parte superior de la pieza. Sus características técnicas apuntan a un encuadre dentro del GT2 y del GT4. Los paralelos de esta tipología podrían encontrarse de nuevo en la zona del sudeste peninsular (GUTIÉRREZ, 1996: 91), pero también en el occidente andalusí (DE ALARCÃO, 1975: lám. XLIII, fig. 830), restringidas a ámbitos de distribución regionales en los que se han propuesto unas cronologías comprendidas entre los siglos IX y $X$.

Finalmente, el último grupo de cerámicas presentado ha sido el correspondiente a las tipologías destinadas a usos diversos, en las que únicamente disponemos del caso del BARREÑO1 para cronología anterior al califato. Se trata de un contenedor de grandes dimensiones, realizado con inclusiones de gran 
tamaño y levantado posiblemente a mano, a juzgar por las abundantes marcas de digitaciones a lo largo de toda su superficie. Esta pieza cuenta además con motivos ungulados en su borde y fue cocida en una atmosfera muy irregular, lo que nos hace plantearnos su inclusión dentro del GT3. El tosco alisado que presentan sus paredes puede haber estado relacionado con una finalidad de impermeabilización de la pieza con el objetivo de evitar filtraciones de líquidos, por lo que pensamos que la pieza debía estar asociada a la realización de la colada o de abluciones. Con paralelos morfológicamente similares desde la segunda mitad del siglo IX en la ciudad de Valencia (PASCUAL et alii, 2003: 110), en el sudeste peninsular (GUTIÉRREZ, 1996: 94-95) y en el área andaluza (KIRCHNER, 1990: lám. 26, fig. 157), no podemos precisar esta vaga cronología más allá de estos datos.

A modo de conclusión, los materiales tardo-antiguos que aparecen en contextos excavados relacionados principalmente con las antiguas villae bajo-imperiales y con las transformaciones que vivieron durante el período visigodo, marcarían una serie de pautas que se pueden observar de forma generalizada en algunos yacimientos de primera época andalusí. En este primer horizonte productivo, vinculado al período entre los siglos VII y VIII, se han intentado aislar algunas formas, como las de los tipos OLLA1 y OLLA2, con un proceso de cocción con ausencia de oxígeno o aportes muy irregulares durante el enfriamiento y decoraciones estriadas o peinadas en el cuello que marcan los primeros niveles de ocupación. Similares a estas, el tipo JARRA1 también parece estar bien documentado en el registro de este horizonte, como un claro ejemplo de la polifuncionalidad que se busca dentro de este modelo productivo. Otro de los tipos de servicio de mesa, el JARRITO1, podría ser también característica de estos mismos contextos. También las cazuelas hechas a mano o con técnicas de modelado muy simples, sin decoraciones ni tratamientos superficiales, inclusiones de tamaño moderado y procesos de cocción muy irregulares podrían vincularse a este horizonte, principalmente los tipos CAZUELA1 y CAZUELA2.
En contextos de excavación este tipo de materiales, pertenecientes al período de transición que comprende el siglo anterior y posterior a la conquista de la Península Ibérica por los ejércitos musulmanes, resulta fuertemente indicativo al ocupar en muchos casos contextos superpuestos de difícil distinción. En el caso de las ollas, las excavaciones en la Plaça de l'Olivera (Tortosa) o en el conjunto episcopal visigodo de la ciudad de Valencia, sirven con claridad para mostrar estas primeras producciones (CURTO et alii, 1984: 14; BLASCO et alii, 1994: 370-372; PASCUAL et alii, 2003: 108; RIBERA, 2008: 317-318), que pueden observarse igualmente en ámbitos más lejanos como el sureste peninsular pero de forma minoritaria respecto a otras formas. También las cazuelas nos permiten intuir esta tendencia continuista en las producciones cerámicas, con ejemplos aparecidos en contextos islámicos y de posible influencia tardo-antigua, como hemos advertido. Así pues, se observa en conjunto una preferencia morfológica por piezas polivalentes y de utilidad básica y una menor diversificación de series, uniendo en un único elemento las funciones que podían haber desarrollado dos grupos tipológicos diferentes en contextos más antiguos. En cualquier caso, no se trata de una involución tecnológica, sino de la respuesta a unas necesidades concretas más sencillas y a un nuevo modelo basado en circuitos distributivos de ámbito regional.

Se plantea, pues, un segundo horizonte productivo con unas formas de manufactura más desarrolladas a partir del siglo IX, momento en el que se establece en esta área el extremo oriental de la Marca Superior de al-Andalus (NEGRE, 2013: 301 y sig.). En este momento seguiría existiendo una cierta continuidad en algunas producciones, siendo un ejemplo de esta tendencia los diversos tipos de cántaros estudiados. Estos también presentan paralelos difíciles de obviar, principalmente con materiales de contextos tardo-antiguos de algunas importantes ciudades cercanas, como con los ejemplos analizados de Tarragona, Mataró, Terrassa o Valencia. Su documentación entre las formas productivas del siglo IX nos permite inferir bien unos primeros ejemplos no 
localizados de esta serie en contextos del siglo VIII, bien la pervivencia de los contenedores tardo-antiguos durante dicha centuria y su evolución hacia estas formas a partir de este nuevo horizonte productivo.

Entre las características más significativas de este momento se podría considerar también la introducción de nuevos tipos de hornos que permiten la entrada de oxígeno durante la fase de enfriamiento de las piezas, dando lugar a piezas de un característico tono rojizo. Aparecen también nuevos motivos decorativos, principalmente las acanaladuras, que serían también característicos de este horizonte. Estos cambios implican una tecnificación cada vez mayor de los modelos productivos de esta zona, principalmente en el ámbito urbano, un hecho que asociamos a la consolidación de la autoridad pública omeya en este distrito. A partir del siglo X se observa una introducción de diversas técnicas de revestimiento arcilloso o esclarecimiento superficial, que se utilizarían abundantemente en la mejora de series anteriores, como sucede en el caso de los cántaros. También puede advertirse una mayor diversificación de los grupos morfológicos, con nuevos tipos y series, como el barreño. El conjunto de piezas de este horizonte, además, se mantendría vigente en el ámbito de Tortosa durante todo el califato, momento en el cual se introducirían nuevas formas y modelos decorativos de origen cordobés, pero que en contadas ocasiones supondrían la desaparición de los tipos morfológicos regionales. En todo caso, algunos de estos grupos podrían haber descrito un nuevo proceso de desarrollo productivo a partir de este momento, depurando sus pastas, dotándose de engobes o vidriados e introduciendo nuevos motivos decorativos.

\section{REFLEXIONES FINALES}

Lo que observamos durante el período en el que hemos centrado nuestro estudio, por tanto, son los primeros estadios evolutivos del proceso de transformación entre el mundo antiguo y el islámico, que a pesar de no ser tan acentuado en un primer momento, sí presenta una serie de rasgos y características propias. Los horizontes que hemos planteado respecto a las producciones cerámicas, uno entre los siglos VII y VIII y otro entre el IX y X responden a su vez a unos horizontes sociales diferenciados. A pesar de la ruptura política que supone la segunda década del siglo VIII, no es menos cierto que ya durante la centuria anterior se había empezado a desarrollar un modelo social distinto al antiguo, basado en unos ámbitos de acción más reducidos y en la diversificación en la explotación de territorios más modestos. Este modelo seguirá vigente durante las primeras décadas del siglo VIII y poco a poco se irá transformando hacia un sistema diferente, de clara influencia urbana y del que podríamos establecer su génesis en los albores del siglo IX, al menos en lo que respecta al territorio de Tortosa.

El estudio de la cerámica alto-medieval de este territorio pretende convertirse en una herramienta para lograr un mejor conocimiento de la estructura social de la zona de trabajo. Esta, junto con otros factores clave como las informaciones que aportan las fuentes escritas o otros tipos de indicadores históricos, deberían con el tiempo permitirnos estudiar de forma más detallada el proceso de cambio social y cultural que se desarrolla en el ámbito tortosino. Para estudiar una dinámica histórica tan compleja como lo es el proceso de islamización de al-Andalus resulta necesario definir antes el alcance y los límites de este concepto. Entendemos que se trata, por tanto, de uno de los ejes fundamentales en el estudio de al-Andalus en tanto que su culminación la convierte en una sociedad plenamente islámica, aunque con sus propias particularidades. Entre estos factores característicos podemos destacar la amplia interacción que esta mantuvo con la formación social previa, así como las fuertes tensiones ocasionadas entre los distintos grupos que configurarían los diferentes esquemas organizativos existentes (ACIÉN, 1989: 141-142).

Hay diversos factores que nos permiten observar el grado de desarrollo de este proceso de forma diacrónica, entre los que pode- 
mos destacar la hegemonía de la propiedad privada y del mundo urbano, la estandarización de los modelos productivos que sirven a su vez de elementos propagandísticos de la autoridad pública o la articulación y diversificación de nuevas formas de explotación del espacio rural, entre otras (NEGRE, 2013: 570-576). La disparidad de ritmos e intensidades que adquieren estas dinámicas dependiendo de cada territorio dificulta en gran medida su comprensión y nos obliga a realizar exhaustivos trabajos de análisis histórico de carácter regional, en los que la cerámica se ha mostrado como uno de los elementos clave para su lectura (GUTIÉRREZ, 2011: 191-192). Creemos por tanto que la transformación de los modelos productivos puede ser leída como un reflejo claro de las dinámicas sociales, políticas e ideológicas que se desarrollaron en el ámbito peninsular entre la desarticulación del mundo antiguo y la consolidación de una nueva sociedad islámica occidental. La secuenciación de este registro arqueológico en diversas fases nos permitiría observar sus cambios como consecuencias materiales de unos determinados procesos históricos. Esta reflexión se basa en la premisa de que aunque estas transformaciones no pueden observarse a partir de diferentes elementos aislados, la suma de todas estas entidades relacionadas entre sí nos permitirá plantear unas determinadas tendencias generales.

Un primer objetivo, que no único, del estudio de los contextos arqueológicos es por tanto el de proporcionar unas dataciones de base a los diferentes niveles de un yacimiento excavado o, en términos más generales, a uno prospectado. Estos marcos cronológicos de referencia son los que nos permiten establecer una serie de hitos con los que analizar la transformación, en este caso, de los modelos técnicos de manufactura cerámica. Una segunda finalidad, mucho más complicada de obtener a partir de registros descontextualizados, es la caracterización de espacios sociales y necesidades funcionales en el interior de un yacimiento. A pesar de las limitaciones de nuestros contextos, también hemos podido observar algunas dinámicas generales al respecto, como por ejemplo la masiva presencia de contenedores de líquidos en asentamientos que probablemente no disponían de un acceso simple a recursos hídricos.

A pesar de la existencia de una gran variedad de tipologías de artefactos que podrían permitirnos estudiar diversos aspectos del registro arqueológico, la cerámica constituye, por su abundancia y diversidad, el principal indicador cronológico y contextual de las sociedades pretéritas. Su potencial será aún mayor cuando consigamos obtener conjuntos cerámicos procedentes de contextos estratigráficos bien estudiados, aunque el estudio relacional de los contextos de prospección o de fondos de museo puede permitirnos esbozar unas líneas generales en torno a sus cronologías y funciones. Pensamos que la clasificación crono-tipológica propuesta para el distrito de Tortosa (Lám. 1) es una herramienta útil en el estudio diacrónico del poblamiento, así como un indicador claro de la transformación de esta área entre la Antigüedad y la Edad Media. Podemos observar cómo, con respecto a otras zonas de la Península Ibérica bajo dominio andalusí, el estudio cerámico que presentamos llega con décadas de retraso (BAZZANA, 1986; GUTIÉRREZ, 1988; ACIÉN Y MARTÍNEZ, 1989; RETUERCE, 1990), por lo que el camino que queda por recorrer es aún muy largo.

\section{AGRADECIMIENTOS}

Quisiera hacer explícito mi agradecimiento al profesor Ramon Martí, de la Universitat Autònoma de Barcelona, por sus acertadas observaciones a este texto. También debo remarcar la ayuda que han supuesto los comentarios y matizaciones de la Dra. Sonia Gutiérrez, de la Universitat d'Alacant, así como la colaboración de Jordi Aguelo en la digitalización de las piezas. Finalmente, los comentarios de los diversos evaluadores del texto han supuesto una importante mejora en el texto definitivo. Pese a sus indicaciones, cualquier error es únicamente responsabilidad del autor. 


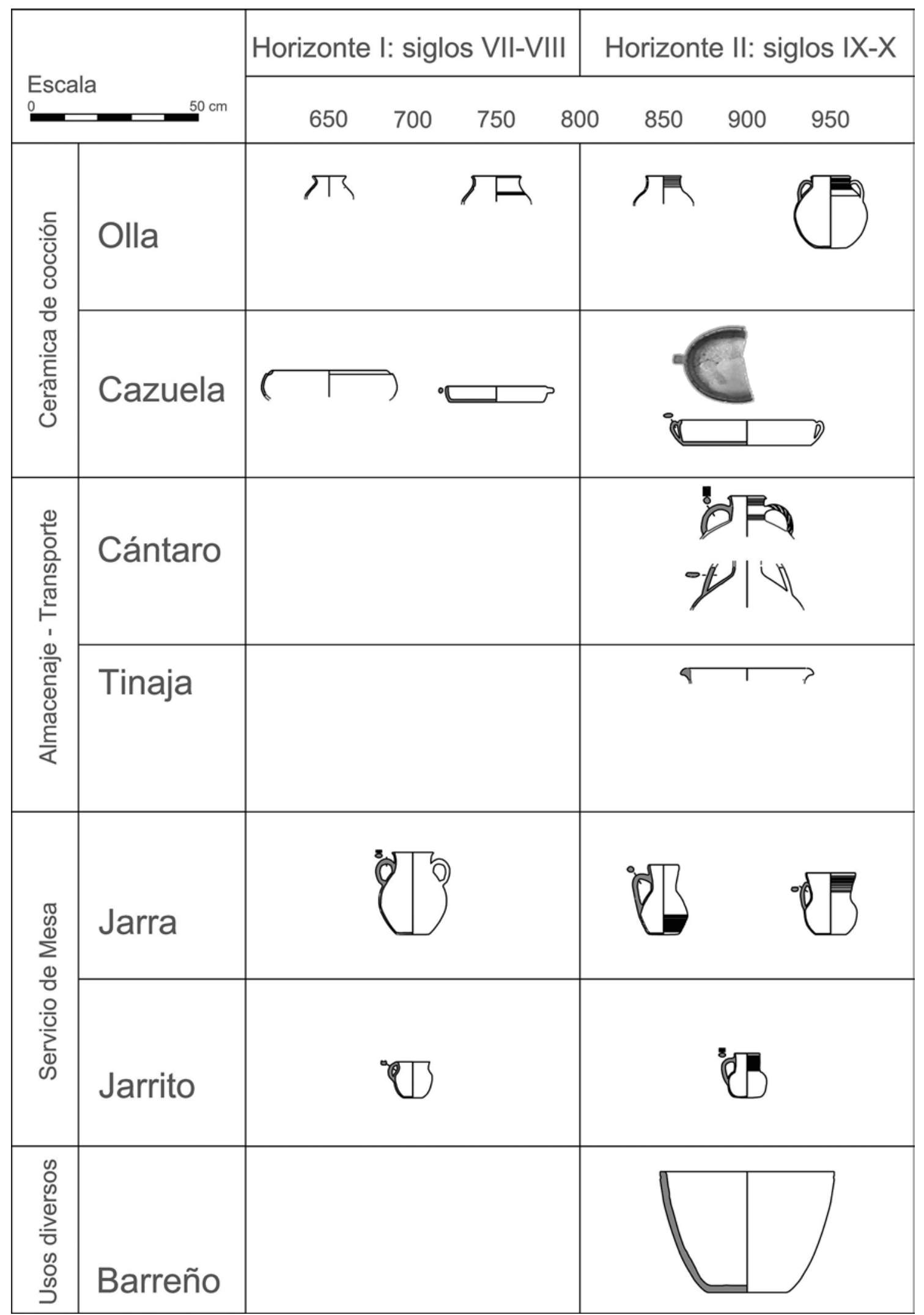

Lámina 1. Series cronotipológicas basadas en sus características morfológicas y técnicas 


\section{BIBLIOGRAFÍA}

ACIÉN, Manuel (1986): "Cerámica a torno lento en Bezmiliana. Cronología, tipos y difusión”, I Congreso de Arqueología Medieval Española, vol. IV. Zaragoza, Universidad de Zaragoza, pp. 243-267

ACIÉN, Manuel (1989): "Poblamiento y fortificación en el sur de al-Andalus. La formación de un país de hușūn", III Congreso de Arqueología Medieval Española. Öviedo, Universidad de Oviedo, pp. 135-150

ACIÉN, Manuel (1993): "La cultura material de época emiral en el sur de Al-Andalus. Nuevas perspectivas", en Malpica, A. (ed.) La cerámica Altomedieval en el Sur de AlAndalus. Granada, Universidad de Granada, pp. 153-172

ACIÉN, Manuel y MARTínEZ, Rafael (1989): "Cerámica islámica arcaica del Sureste de Al-Andalus", Boletín de Arqueología Medieval. 3, pp. 123-135

ACIÉN, Manuel; CRESSIER, Patrice; ERBATI, Larbi y PICON, Maurice (1999): "La cerámica a mano de Nakūr (ss. IX-X). Producción beréber medieval”, Arqueología y Territorio Medieval. 3, pp. 45-69

ALBA, Miguel y GUTIÉRREZ, Sonia (2008): "Las producciones de transición al Mundo Islámico: el problema de la cerámica paleoandalusí (siglos VIII y IX)", en Bernal, D. y Ribera, A. (eds.) Cerámicas hispanorromanas. Un estado de la cuestión. Cadiz, Universidad de Cádiz, pp. 585-613.

ALÒS, Carme y SOLANES, Eva (2010): Catàleg de la colecció de materials andalusins del Museu de la Noguera. Balaguer, Museu de la Noguera.

BALLESTÍN, Xavier (1994): "Prosopografia dels fuqahā' i 'ulamā' de la zona oriental de al-Tagr al-Álà: Balagà, Lārida i Turțūša", Estudios Onomástico-Biográficos de al-Andalus. 6, pp. 55-119

BALLESTín, Xavier (1995): "Prosopografia dels fuqahā' i 'ulamā' de la zona oriental de al-Tagr al-Alà: Balaga, Lārida i Turțūša (II)", Estudios Onomástico-Biográficos de al-Andalus. 7, pp. 489-532

BALLESTÍN, Xavier (1999): "L'anomenada Frontera Superior d'al-Andalus: at-Tagr al-a'là i la resistència a la instauració de la dawla dels Banū Marwān", en Barceló, M. (ed.) Musulmans i Catalunya. Barcelona, Empúries, pp. $61-78$

BAZZANA, André (1986): "Essai de typologie des ollas valenciennes", Actas del II Coloquio de Cerámica Medieval del Mediterráneo Occidental. Toledo, Ministerio de Cultura, pp. 93-98.

BAZZANA, André (1990): "Ensayo de tipología de la cerámica musulmana del antiguo Sharq Al-Andalus", en Bazzana, A. (ed.), La cerámica islámica en la ciudad de Valencia. 2 volúmenes, Valencia, Ajuntament de València, pp. 143-162

BAZZANA, André; LEMOINE, Charlotte y PICON, Maurice (1986): "Le problème de l'origine et de la diffusion des céramiques dites califales: recherche préliminaire», Actas del II Coloquio Internacional de Cerámica Medieval en el Mediterráneo Occidental. Madrid, Ministerio de Cultura, pp. 33-38
BELTRÁN, Julia (2005): "Las producciones locales e importaciones de la cerámica común del yacimiento de la Plaza del Rei de Barcelona, entre la época visigoda y el periodo islámico. Siglos VI-VIII". Quarhis: Quaderns d'Arqueologia i Història de la Ciutat de Barcelona. 1, pp. 68-89

BLASCO, Juli; ESCRIVÀ, Vicent y SORIANO, Rafaela (1994): "Assaig de síntesi del panorama ceràmica de la ciutat de València a l'Antiguitat Tardana", Actes de la III Reunió d'Arqueologia Cristiana Hispànica. Barcelona, Institut d'Estudis Catalans, pp. 357-373.

BRAMON, Dolors (2000): De quan érem o no musulmans. Textos del 713 al 1010. Barcelona, Eumo

BULLIET, Richard (1979): Conversion to Islam in the medieval period: an essay in quantitative history. Cambridge, Harvard University Press.

CANO, Encarnación (2007): "Formas cerámicas representativas de la ocupación de cuevas naturales, durante la Edad Media andalusí, en el entorno de Madinat Baguh (Priego de Córdoba)». Antiquitas. 18-19, pp. 141-168

CAPELLI, Claudio y CABELLA, Roberto (2004): "Note sulla caratterizzazione dei rivestimenti delle ceramiche medievali", en Giannichedda, E. (ed.) Metodi e pratica della cultura materiale. Produzione e consumo dei manufatti. Bordighera, Istituto Internazionale di Studi Liguri, pp. 125-132

CAPELLI, Claudio y MANNONI, Tiziano (1996): "I problemi dei rivestimenti nelle fabbriche italiane del XIII secolo". Atti del XXIX Convegno Internazionale della Ceramica, Florencia, All'Insegna del Giglio, pp. 229-233.

CASAL, Maria Teresa; CASTRO, Elena; LÓPEZ, Rosa y SALINAS, Elena (2005): "Aproximación al estudio de la cerámica emiral del arrabal de Šaqunda (Qurțuba, Córdoba)". Arqueología y Territorio Medieval. 12/2, pp. 189-235

CASTILLO, Juan Carlos (1996): "La cerámica emiral de la campiña de Jaén”. Arqueología y Territorio Medieval. 3, pp. $191-220$

CASTILLO, Francisco; MARTíNEZ, Rafael y ACIÉN, Manuel (1986): "Urbanismo e industria en Bayyana, Pechina (Almería)". Segundo Coloquio Internacional de Cerámica Medieval en el Mediterráneo Occidental. Madrid, Ministerio de Cultura, pp. 539-548

CELA, Xabier y REVILLA, Victor (2004): La transició del municipium d'lluro a Alarona (Mataró). Cultura material i transformacions d'un espai urbà entre els segles V i VII dC. Mataró, Museu de Mataró.

CURTO, Albert; LORIENTE, Ana y MARTÍNEZ, Rosario (1984): Plaça de l'Olivera o de la Cinta. Segona campanya. Documento técnico restringido, Barcelona, Dirección General del Patrimonio Cultural.

CURTO, Albert; LORIENTE, Ana; MARTÍNEZ, Rosario y ROS, Elisa (1986): "Els nivells islàmics en l'excavació en la plaça de Ntra. Sra. de la Cinta o de l'Olivera de la ciutat de Tortosa (Tarragona)". I Congreso de Arqueología Medieval Española. Zaragoza, AEAM, pp. 99-112 
CURTO, Albert y MONTAÑÉS, Cinta (2009): Turtuxa, a l'extrem d'al-Àndalus. Tortosa, Museu de Tortosa, Històric i Arqueològic de les Terres de l'Ebre.

DE ALARCÃO, Jorge (1975): Fouilles de Coninmbriga: céramiques diverses et verres, vol. V. Paris, Boccard.

ESQUIVEL, José Antonio (1988): Una aplicación de la entropía al Análisis Cluster mediante variables cualitativas multi-estado: afinidad, similaridad y agrupación. Tesis doctoral, Universidad de Granada

ESQUIVEL, José Antonio; CAPEL, Josefa; CONTRERAS, Francisco y MOLINA, Fernando (1991): "Una aplicación de la Teoría de la Información al análisis de datos definidos mediante variables calitativas multi-estado: medidas de similaridad y análisis cluster", Complutum. 1, pp. 53-70

GARCIA, David (2000): Excavació de la vil·la romana de la Carrova (Amposta, Montsià). Document tècnic restringit, Direcció General del Patrimoni Cultural

GRIÑÓ, Damià; CAMARASA, Vanesa y KIRCHNER, Helena (2013): "La intervenció arqueològica al Castell de la Suda, Parador Nacional de Turisme (Tortosa, Baix Ebre)”. Actes del IV Congrés d'Arqueologia Medieval i Moderna a Catalunya, Ajuntament de Tarragona - ACRAM, pp. 349-360

GUTIÉRREZ, Sonia (1988): Cerámica común paleoandalusí del sur de Alicante (siglos VII-X). Alacant, Caja de Ahorros Provincial

GUTIÉRREZ, Sonia (1996): La Cora de Tudmir de la Antigüedad Tardía al mundo islámico: poblamiento y cultura material. Madrid, Casa de Velázquez.

GUTIÉRREZ, Sonia (1999): "La cerámica emiral de Madinat lyih (el Tolmo de Minateda, Hellín, Albacete). Una primera aproximación". Arqueología y Territorio Medieval. 6, pp. 71-111

GUTIÉRREZ, Sonia (2007): "La islamización de Tudmîr: balance y perspectivas", en Sénac, Ph. (ed.) Villa2 - Villes et campagnes de Tarraconaise et d'al-Andalus (VIe-Xle siècles): la transition. Toulouse, Université de Toulouse II - Le Mirail, pp. 275-318.

GUTIÉRREZ, Sonia (2011): "El reconocimiento arqueológico de la islamización. Una mirada desde al-Andalus", 711. Arqueología e Historia entre dos mundos, vol. I. Alcalá de Henares, Museo Arqueológico Regional, pp. 191-210

GUTIÉRREZ, Sonia; GAMO, Blanca y AMORÓS, Victoria (2003): "Los contextos cerámicos altomedievales del Tolmo de Minateda y la cerámica altomedieval en el sudeste de la península ibérica", en Caballero, L.; Mateos, P. y Retuerce, M. (eds.) Cerámicas Tardorromanas y altomedievales en la Península Ibérica. Ruptura y Continuidad (Anejos de AEspA XXVIII). Madrid, CSIC - Instituto de Arqueología de Mérida / Instituto de Historia, pp. 119-168

KIRCHNER, Helena (1990): Étude des céramiques islamiques de Shadhīlah (Setefilla, Lora del Rio, Séville). Lyon, Université de Lyon

LORIENTE, Ana (2000): "La vaixella andalusina de la primera meitat del segle X apareguda a la ciutat de Lleida”, Revista d'Arqueologia de Ponent. 10, pp. 293-318
MACIAS, Josep Maria (1999): La ceràmica comuna tardoantiga a Tàrraco. Anàlisi tipològica i històrica (segles V-VII). Tarragona, Museu Nacional Arqueològic de Tarragona

MACIAS, Josep Maria y REMOLÀ, Josep Anton (2000): "Tarraco visigoda: caracterización del material cerámico del siglo VII dC", Actes de la V Reunió d'Arqueologia Cristiana Hispànica. Barcelona, Institut d'Estudis Catalans, pp. 485-497.

MACIAS, Josep Maria y REMOLÀ, Josep Anton (2005): "La cultura material de Tarraco-Tarracona (Hispania Tarraconensis-Regnum Visigothorum: cerámica común y ánforas", en Gurt, J.M.; Bruxeda, J. y Cau, J.M. (eds.) LRCW1. Late Roman Coarse Wares, Cooking Wares and Amphorae in the Mediterranean. Archaeology and Archaeometry. Oxford, BAR International Series, pp. 125-135.

MARTÍ, Ramon (1992): "L'expansió del comtat de Barcelona a ponent de Llobregat”, Catalunya Romànica, vol XIX. Barcelona, Enciclopèdia Catalana, pp. 28-35

MARTÍ, Ramon y SELMA, Sergi (1997): "La torre emiral de Malpàs (Castellnovo, Alt Palància)", Annals de l'Institut d'Estudis Gironins. 38, pp. 1383-1398

MONTMESSIN, Yves (1980): "Description analytique de la céramique commune du testar de Onda/Mas de Pere (Castellón)», Cuadernos de prehistoria y arqueología castellonenses. 7, pp. 243-290

NAVARRO, Julio (1990): "Los materiales islámicos de Alfar antiguo de San Nicolás de Murcia”, en Amigues, F. y Bazzana, A. (eds.) Fours de poitiers et "testares" médiévaux en Méditerranée Occidentale. Méthodes et résultats. Madrid, Casa de Velázquez, pp. 29-43

NEGRE, Joan (2013): De Dertosa a Turțūša. L'extrem oriental d'al-Tagr al-A'là en el context del procés d'islamització d'al-Andalus, Tesis doctoral, Universitat Autònoma de Barcelona (http://www.tdx.cat/handle/10803/116319)

NEGRE, Joan y MARTí, Ramon (2013): Memòria de les prospeccions arqueològiques a les Terres de l'Ebre, Documento técnico restringido, Direcció General del Patrimoni Cultural - Generalitat de Catalunya

NOLLA, Josep Maria y CASAS, Josep (1997): "Material ceràmic del Puig de les muralles (Puig Rom, Roses)", en Arqueomediterrania. Contextos ceràmics d'època romana tardana i de l'Alta Edat Mitjana (segles IV-X). Barcelona, Universitat de Barcelona, pp. 7-19

PASCUAL, Josefa; RIBERA, Albert; ROSSELLÓ, Miquel y MAROT, Teresa (1997): "València i el seu territori: contexts ceràmics de la fi de la romanitat a la fi del califat (270-1031)", Arqueomediterrània. Contextos ceràmics d'època romana tardana i de l'Alta Edat Mitjana (segles IV-X). Barcelona, Universitat de Barcelona, pp. 179-202.

PASCUAL, Josefa; RIBERA, Albert y ROSSELLÓ, Mique (2003): "Cerámicas de la ciudad de Valencia entre la época visigoda y omeya (siglos VI-X)", Anejos de AEspA. 28, pp. 67-117.

RAMS, Pere y PÉREZ, Josep Maria (2003): Intervenció arqueològica a l'entorn de la Torre de l'Ermita de la Mare de Déu de l'Aldea. Documento técnico restringido, Direcció General del Patrimoni Cultural 
REMOLÁ, Josep Anton (2000): Las ánforas tardo-antiguas en Tarraco (Hispania Tarraconensis). Barcelona, Universitat de Barcelona

REMOLÀ, Josep Anton; BENET, Cristina y MACIAS, Josep Maria (1991): Memoria de la intervenció arqueològica realitzada al Mas del Catxorro. Documento técnico restringido, Direcció General del Patrimoni Cultural

RETUERCE, Manuel (1990): "Cerámica islámica en la comunidad de Madrid", Madrid del siglo IX al XI. Madrid, Dirección General de Patrimonio Cultural, pp. 145-164

REVILLA, Victor (2004): Economia i poblament romà al curs inferior de l'Ebre: la vil.la de la Casa Blanca (Tortosa). Tarragona, Diputació Provincial de Tarragona

RIBERA, Albert (2008): "La ciudad de Valencia durante el período visigodo", Zona Arqueológica. 9, pp. 303-320

ROSSELLÓ, Miquel (1999): "Evolució i tranformació de l'espai urbà des de l'Època emiral fins a l'Ėpoca taifa: les excavacions del C/ Comte Trènor, 12 (València)", Actes del I Congrés d'Estudis de l'Horta Nord. Valencia, Centre d'Estudis de l'Horta Nord, pp. 57-87
ROSSELLÓ BORDOY, Guillermo (1978): Ensayo de sistematización de la cerámica árabe de Mallorca. Palma de Mallorca, Institut d'Estudis Baleàrics

ROSSELLÓ BORDOY, Guillermo (1991): El nombre de las cosas en al-Andalus: una propuesta de terminología cerámica. Palma de Mallorca, Museu de Mallorca

SALINAS, Elena (2012): "Las primeras producciones vidriadas de época emiral en Córdoba (España)". Atti del IX Congresso Internazionale sulla Ceramica Medievale nel Mediterraneo. Florencia, All'Insegna del Giglio, pp. 230-235

SÁNCHEZ, Eduard; DEFAUS, J.M y PALET, J.M. (1989): Memòria de les excavacions al jaciment de l'Aiguacuit. Documento técnico restringido, Direcció General del Patrimoni Cultural

SOLER, Maria Paz (1988): Historia de la Cerámica Valenciana. Vol. II. Valencia, Vicent Garcia. 